\title{
Las necrópolis protohistóricas tumulares de Cataluña meridional: el ejemplo de Sebes (Flix, Tarragona)
}

\author{
Protohistoric tumular necropolis in southern Catalonia: the example of Sebes \\ (Flix, Tarragona)
}

Maria Carme Belarte (*)

Assumpció Malgosa (**)

Jaume Noguera $(* * *)$

Pau Olmos (****)

Giampaolo Piga (*****)

\section{RESUMEN}

Se presentan los resultados de las recientes intervenciones arqueológicas realizadas en la necrópolis del Hierro I de Sebes (Flix, Tarragona). Se ha precisado la extensión de la necrópolis, su duración, los rituales funerarios y la estructura social de la población mediante técnicas y métodos de carácter interdisciplinar (antropología, carbono 14, prospecciones geofísicas...). Se ha constatado la coexistencia de túmulos y urnas y la agrupación de las estructuras en dos áreas. Sobre esta base se pretende mejorar el conocimiento de las necrópolis de cremación en un territorio de contacto entre diferentes tradiciones de enterramiento. Se dan a conocer datos inéditos procedentes del estudio antropológico de los huesos cremados de Sebes y de las dataciones radiocarbónicas de algunos de ellos. Estos datos, considerados en conjunto con los del resto de la necrópo-

(*) Institució Catalana de Recerca i Estudis Avançats (ICREA), Institut Català d'Arqueologia Clàssica (ICAC). Pl. del Rovellat s/n. 43003 Tarragona, España. Correo e.: cbelarte@icac.cat

(**) Grup de Recerca en Osteobiografia (GROB). Unitat d'Antropologia Biològica, Departament de Biologia Animal, Biologia Vegetal i Ecologia, Facultat de Biociències, Universitat Autònoma de Barcelona, Campus de Bellaterra. 08193 Bellaterra - Cerdanyola del Vallès, España. Correo e.: assumpcio.malgosa@uab.cat

$(* * *)$ Departament de Prehistòria, Història Antiga i Arqueologia, Facultat de Geografia i Història, Universitat de Barcelona. C/ Montalegre 6.00801 Barcelona, España. Correo e.: noguera@ub.edu

$(* * * *)$ Institut Català d'Arqueologia Clàssica (ICAC). Pl. del Rovellat s/n. 43003 Tarragona, España. Correo e.: polmos@icac.cat

(*****) Grup de Recerca en Osteobiografia (GROB). Unitat d'Antropologia Biològica, Departament de Biologia Animal, Biologia Vegetal i Ecologia, Facultat de Biociències, Universitat Autònoma de Barcelona. Campus de Bellaterra. 08193 Bellaterra - Cerdanyola del Vallès, España. Correo e.: kemiomara@yahoo.it lis, permiten relacionarla más con las necrópolis tumulares leridanas que con las del Bajo Aragón - Terra Alta.

\begin{abstract}
We present the results of recent research in the Early Iron Age necropolis of Sebes (Flix, Tarragona). They include the delimitation of the necropolis surface and its duration, the analysis of the funerary rituals as well as the social structure of its population through the use of interdisciplinary methods and techniques (anthropology, radiocarbon dating, geophysical surveys,...). The coexistence of tumuli and urns as well as the association of structures in two areas is confirmed. On this basis we aim to improve our knowledge of the cremation necropolis in a territory where different burial traditions were in contact. Unpublished data coming from the anthropological study of cremated bones and from the radiocarbon dating of these remains are presented. These data, considered within all the information gathered from the necropolis, show that it is closer to the tumular necropolis of the Lleida area than to the burial sites of the Low Aragón and Terra Alta regions.
\end{abstract}

Palabras clave: Península Ibérica; Necrópolis de cremación; Poblamiento del Bajo Ebro; Arqueología de la muerte; Ritual funerario; Antropología; Datación radiocarbónica; Cronología absoluta; Tipología cerámica; Análisis de isótopos de plomo; Ánfora fenicia.

Key words: Iberian Peninsula; Cremation necropolis; Lower Ebro river population; Archaeology of Death; Funerary ritual; Anthropology; Radiocarbon dating; Absolute chronology; Ceramic Typology; Lead isotope analysis; Phoenician amphora. 


\section{PROBLEMÁTICA Y ESTADO DE LA CUESTIÓN}

La investigación arqueológica realizada en la necrópolis protohistórica de Sebes desde el año 2005 nos ha permitido profundizar en el conocimiento del registro funerario protohistórico en una zona situada entre el Bajo Aragón y el Segre - Bajo Cinca, un territorio con unas características propias, situado entre dos grandes áreas culturales. En Cataluña contamos con un número significativo de necrópolis protohistóricas excavadas. Destacamos las necrópolis de Coll del Moro (Gandesa, Tarragona) (Rafel 1991; Rafel y Hernández 1992), la Pedrera (Vallfogona de Balaguer-Térmens, Lleida) (Vázquez et al. 2012), Can Bech de Baix (Toledo y Palol 2006) o las más recientes de Santa Madrona (Riba-roja d'Ebre, Tarragona) (Belarte y Noguera 2007), Roques de Sant Formatge (Seròs, Lleida) (Colet et al. 2005a), Pi de la Lliura (Vidreres, Girona) (Pons y Solés 2008), Vilanera (l'Escala, Girona) (Agustí et al. 2004) o Can Piteu-Can Roqueta (Sabadell, Barcelona) (Carlús et al. 2007). En la actualidad el conocimiento del registro funerario de las sociedades protohistóricas ha avanzado de modo significativo, ya que por primera vez se han utilizado métodos de excavación y registro, de tratamiento de los resultados, así como de datación que sobrepasan el estudio crono-tipológico de los conjuntos materiales.

El cada vez más importante número de publicaciones monográficas de excavaciones de necrópolis, así como la celebración de reuniones específicas sobre arqueología funeraria, como las celebradas en Barcelona (2008, Rovira Hortalà et al. 2012) o Cádiz (2010), han ampliado notablemente la documentación y han sentado las bases para la aplicación de nuevas metodologías en la investigación.

Los análisis cada vez más exhaustivos paleoantropológicos y paleopatológicos de los restos incinerados, junto a los estudios de arqueozoología y arqueobotánica, han sido claves para el mejor conocimiento de las estructuras sociales y de las características de las poblaciones protohistóricas. Estas investigaciones se han centrado en la revisión de restos procedentes de excavaciones antiguas (Toledo y Palol 2006; Agustí 2008) y en el estudio de los aportados por las nuevas (Fadrique y Malgosa 2007; Subirà y Ruiz 2008).
La datación de los enterramientos y las estructuras destacan entre las principales problemáticas que afectan al registro funerario en época protohistórica. Tradicionalmente, la seriación tipológica de las urnas, el análisis comparativo de los ajuares metálicos (siempre escasos), la morfología de los enterramientos y la superposición de estructuras han establecido la cronología. La datación radiocarbónica sobre huesos cremados aún muestra problemas de fiabilidad y proporciona una horquilla cronológica demasiado amplia (Rafel y Armada 2008), como hemos podido constatar en las dataciones realizadas en Sebes.

\section{EL CONTEXTO CRONOCULTURAL: LAS COMUNIDADES DEL HIERRO I EN EL CURSO INFERIOR DEL EBRO}

Desde mediados del siglo VII a.C. la zona mencionada se caracteriza por la aparición de las primeras aldeas sedentarias. Son pequeños poblados formados por grupos de 10 a 20 casas separadas por paredes medianeras y adosadas a un muro perimetral, organizadas en torno a espacios centrales (Puig Roig, El Masroig; La Ferradura, Ulldecona), calles (Barranc de Gàfols, Ginestar) o en terrazas dispuestas a distintas alturas (Sebes, Flix). Dichos poblados están ocupados por agrupaciones familiares, que colaboran para la obtención de recursos y cuya economía se fundamenta en una agricultura de roza complementada por la ganadería y la recolección (Sanmartí et al. 2006: 148-150). En este contexto, las necrópolis de incineración son un elemento legitimador de la posesión y explotación de las tierras (LópezCachero 2007: 107), expresan la solidaridad del grupo (Ruiz Zapatero 2001: 284) y el carácter sedentario de estas sociedades. En este momento se intensifican las relaciones comerciales con los establecimientos fenicios del sur de la Península Ibérica que posibilitan una acumulación de bienes de prestigio en manos de los jefes de linaje, evidenciada en la aparición de residencias como Aldovesta (Benifallet) (Mascort et al. 1991), en algunos casos fortificadas como Sant Jaume-Mas d'en Serrà (Alcanar) (Garcia y Moreno 2008). Ello, unido a la competencia por los recursos ligada a un aumento demográfico y la falta de mejoras tecnológicas (Sanmartí 2005: 340; Sanmartí et al.

Trab. Prehist., 70, N. ${ }^{\circ}$ 2, julio-diciembre 2013, pp. 295-314, ISSN: 0082-5638

doi: $10.3989 /$ tp.2013.12114 
2006: 150), genera una incipiente jerarquización social. No obstante, las desigualdades sociales son poco evidentes en el registro arqueológico antes del siglo VI a.C. La mayor parte de la información disponible muestra un predominio de casas de superficies similares, así como una escasa desigualdad entre las tumbas y los ajuares de las necrópolis.

\section{EL YACIMIENTO}

\subsection{Introducción}

El yacimiento de Sebes se sitúa en el término municipal de Flix (Tarragona), a unos $2,5 \mathrm{~km}$ al noroeste de la población, a la derecha de la confluencia del barranco de Sant Joan, en la ribera izquierda del río Ebro, dentro de la Reserva Natural de Fauna Salvaje de Sebes y Meandro de Flix (Fig. 1). Ocupa la segunda terraza fluvial situada al oeste del barranco, constituida por dos elementos topográficos bien diferenciados: un terreno llano, a $33 \mathrm{~m}$ sobre el río y con una longitud de $175 \mathrm{~m}$, y una pequeña colina a $55 \mathrm{~m}$ de altura sobre el río y unos $40 \mathrm{~m}$ de ancho, que cierra la plataforma por el lado noroeste. Desde el punto de vista geológico, la zona está constituida por formaciones oligocénicas, que incluyen depósitos de margas, conglomerados calcáreos, areniscas y arcillas.

El yacimiento está formado por restos de diferentes períodos, fundamentalmente de época protohistórica (Belarte y Noguera 2008). La cima y la parte superior de las vertientes de la colina están ocupadas por un asentamiento del Hierro I. La vertiente suroeste, además, conserva restos de un hábitat del período Ibérico Antiguo. Por la parte llana se extiende la necrópolis, en uso durante el Hierro I y, tal vez aún, en época ibérica (Fig. 2). A este conjunto se añade, en el extremo meridional de la terraza y a unos $140 \mathrm{~m}$ al suroeste de la colina, un edificio de planta rectangular, probablemente de época medieval, cuya cronología precisa se desconoce. En época contemporánea, el yacimiento de Sebes formó parte de los escenarios de la batalla del Ebro, como indican una línea de trincheras en el extremo suroeste de la terraza fluvial (Fig. 3A y C) y una posición defensiva sobre la colina.

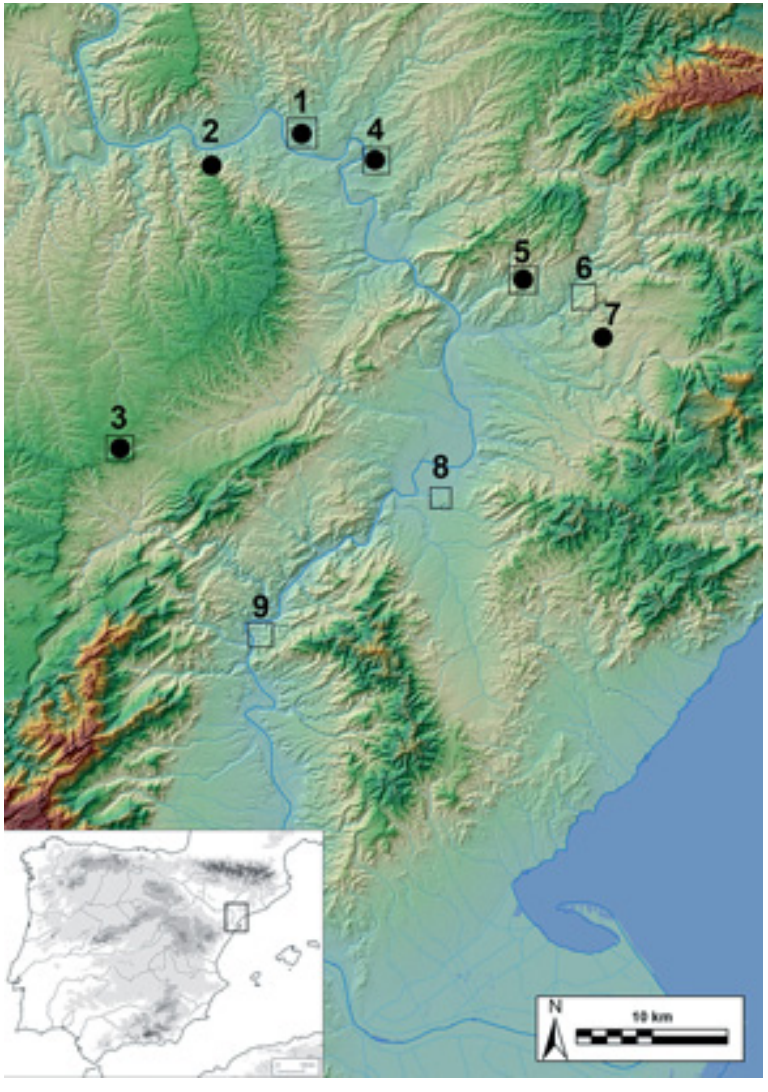

Fig. 1. Mapa del curso inferior del río Ebro con las necrópolis (círculos) y asentamientos (recuadros) del Hierro I citados en el texto. 1. Sebes (Flix); 2. Santa Madrona (Ribaroja d'Ebre); 3. Coll del Moro (Gandesa); 4. Castellons (Flix); 5. El Calvari (Molar); 6. Puig Roig (el Masroig); 7. La Tosseta (Guiamets); 8. Barranc de Gàfols (Ginestar); 9. Aldovesta (Benifallet). Mapa X. Bermúdez, base cartográfica: MDT30 ICC (Institut Cartogràfic de Catalunya).

El yacimiento protohistórico era conocido gracias a hallazgos de superficie previos al inicio de nuestro proyecto. La primera noticia (Pita 1950) indicaba la presencia de cerámica ibérica a torno y de cerámica a mano, que M. Sanz (1973-74) fechó en el siglo IV a.C. M. Genera (1982) diferenció dos zonas del yacimiento por su cronología: una ocupación pre-ibérica sobre la colina y una de época ibérica en el llano adyacente. Finalmente, la Carta Arqueològica (1) situaba el origen de la ocupación en Sebes como mínimo en el siglo VII a.C.

(1) Carta Arqueològica. Ribera d'Ebre. Arxiu d'Inventari del Patrimoni Arqueològic de Catalunya. Servei d'Arqueologia. Generalitat de Catalunya, 1987. Inédito. 


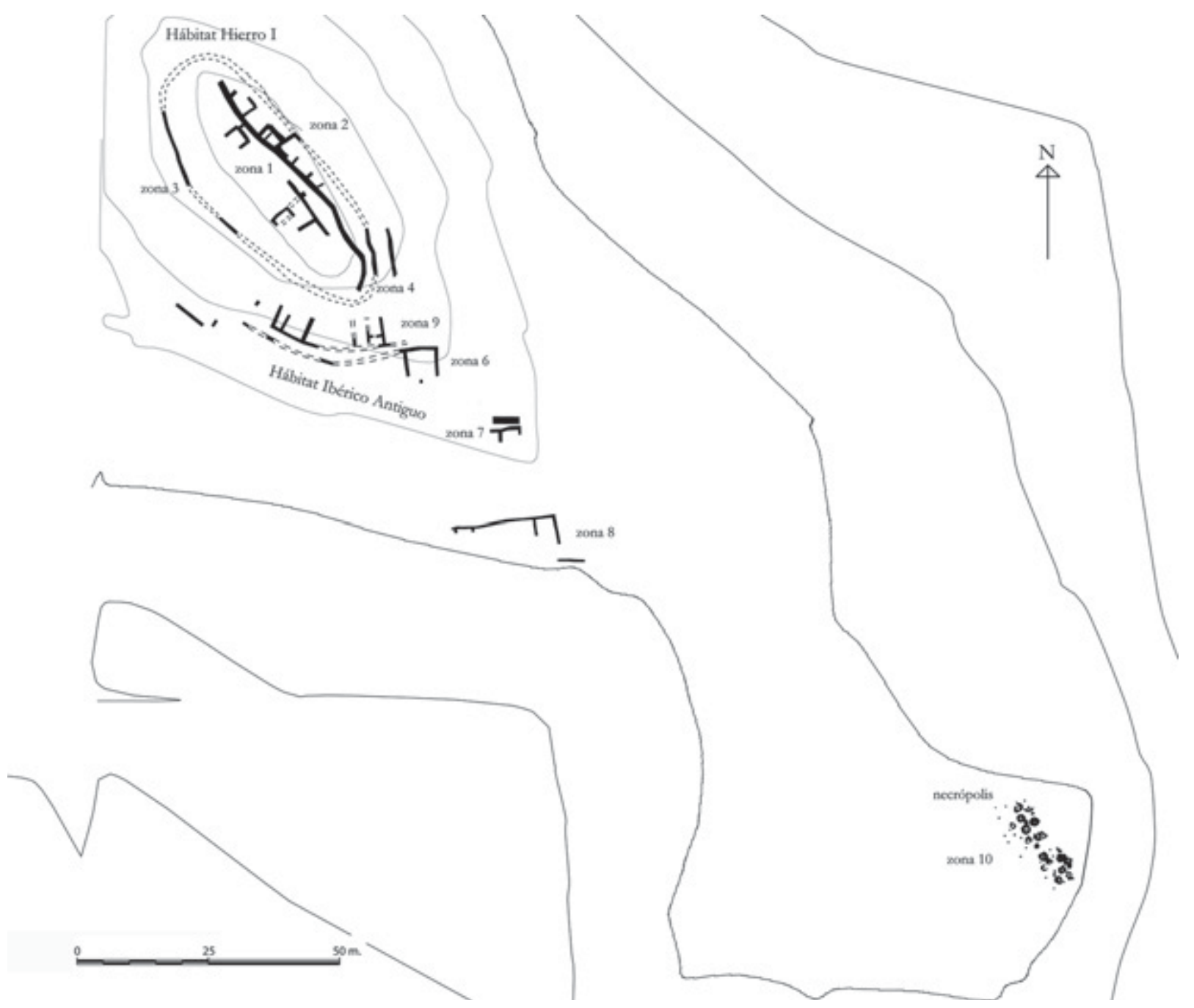

Fig. 2. Planta general de las estructuras domésticas y funerarias de época protohistórica documentadas en el yacimiento de Sebes (Flix, Tarragona).

Nuestra intervención en el yacimiento se inició en 2005 y continúa en curso en la actualidad. Se enmarca dentro del proyecto "Projecte de recerca arqueològica sobre les estratègies d'ocupació del territori i la seva evolució a les comarques del curs inferior de l'Ebre durant la protohistòria i l'antiguitat", y resulta de una colaboración entre el Instituto Catalán de Arqueología Clásica y la Universidad de Barcelo- na, con el patrocinio del Ayuntamiento de Flix, de la asociación La Cana, la Agència de Gestió d'Ajuts Universitaris i de Recerca (AGAUR) y el Departamento de Cultura de la Generalitat de Catalunya. Se ha excavado el asentamiento del Hierro I casi completo (Belarte y Noguera 2008), parte del hábitat del Ibérico Antiguo (Belarte et al. 2012a) y la totalidad de la necrópolis objeto de este artículo. 


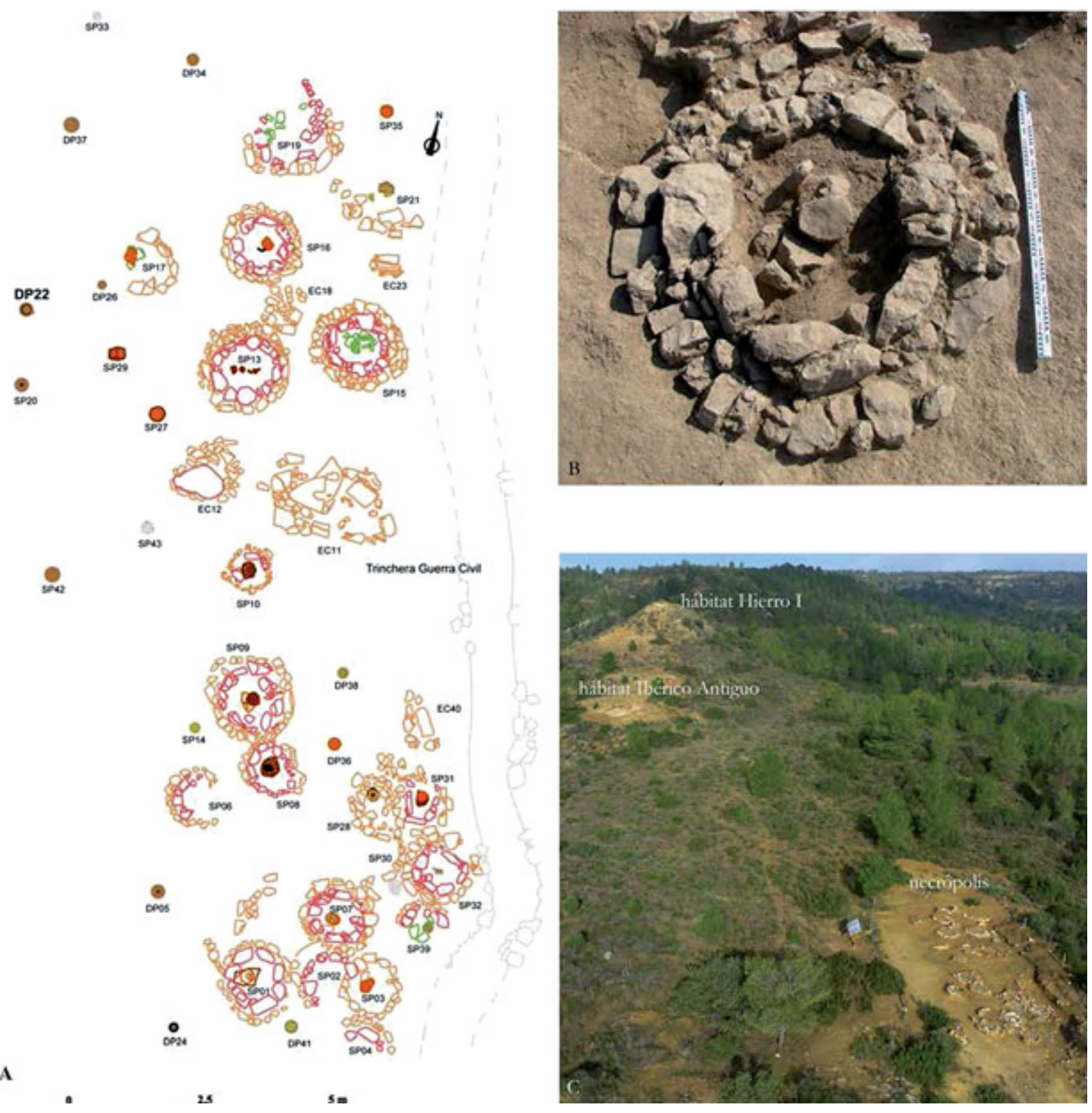

Fig. 3. Necrópolis del Hierro I de Sebes (Flix, Tarragona): A. Planta general de las estructuras documentadas entre 2005 y 2009 desde el Sur (completa Belarte et al. 2012b: 96, fig. 2), donde se destaca la localización de DP22; B. Vista cenital de la estructura tumular SP15; C. Vista aérea de la necrópolis. Al fondo, los dos núcleos de hábitat documentados.

\subsection{Las estructuras documentadas en la necrópolis}

La investigación en el área de la necrópolis se inició con la prospección de la terraza fluvial que se extiende al sureste del hábitat. Se iden- tificaron pequeños fragmentos de huesos calcinados y de cerámica a mano y algunas piedras que podrían delimitar estructuras tumulares. La posterior prospección con detector de metales no recuperó ningún objeto metálico en superficie, ni identificó anomalías magnéticas. Los objetos 
metálicos, hallados durante la excavación, habían perdido toda conductividad por haber sido sometidos a elevadas temperaturas, como veremos más adelante.

Las excavaciones se iniciaron en el extremo sureste de la terraza y paulatinamente se fueron extendiendo hacia el noroeste, en dirección a la colina ocupada por el hábitat. Paralelamente, se prospectó mediante gradiómetro magnético (tipo fluxgate) una superficie de $3.000 \mathrm{~m}^{2}$ para delimitar el área de enterramiento y la posible presencia de ustrina (2). La interpretación de las anomalías sugería una importante extensión de la necrópolis y la presencia de estructuras con indicios de combustión. Sin embargo los sondeos posteriores dieron resultados negativos, de modo que la superficie parece limitarse al área actualmente excavada, de unos $200 \mathrm{~m}^{2}$. Aquí se han documentado 42 estructuras de tipología y función diversa (Fig. 3A). La mayoría están bien conservadas: 20 son estructuras tumulares, 15 urnas depositadas in situ sin relación directa con un túmulo, 2 son concentraciones de huesos agrupados pero sin restos de urna y 5 son estructuras de función indeterminada situadas entre los túmulos (Fig. 3A). Además hay huesos dispersos por la necrópolis (Tab. 1).

El tipo de estructura más característico por su abundancia es un túmulo de planta circular, construido mediante dos anillos concéntricos de piedras salvo cuatro que poseen solo uno. En general, los túmulos presentan una altura de unos $0,20 \mathrm{~m}$ y un diámetro de unos $1,50 \mathrm{~m}$, aunque algunos son más reducidos. Su estratigrafía es simple: el nivel superior está formado por una acumulación de piedras que oculta una gran losa calcárea (Fig. 4). A su vez, esta cubre el osario: una única urna de cerámica a mano tapada con una pequeña losa de piedra recortada. Diez de los túmulos contienen restos óseos cremados, acompañados en ocasiones de ajuares compuestos fundamentalmente por objetos de bronce (que serán descritos más adelante) y, más raramente, restos de sílex retocado. Normalmente, los huesos y el ajuar están contenidos en la urna, pero en ocasiones estos restos se recuperan fuera de ella. Ha sido imposible identificar los loculi o fosas, abiertas en las arcillas naturales para encajar las urnas.

De los 20 túmulos identificados, 15 contenían una urna o parte de ella (SP01, SP03, SP07, SP08, SP09, SP10, SP13, SP16, SP17, SP19, SP21, SP28, SP30, SP31, SP39). Los 5 restantes (SP02, SP04, SP06, SP15, SP32) no conservaban ningún resto de urna, ya sea porque habían desaparecido al estar parcialmente destruidos, ya porque habían sido reutilizados, o bien porque nunca la tuvieron. Los túmulos se disponen en agrupaciones, en algunos casos muy densas, que incluso cortan estructuras anteriores. Algunos de ellos podrían haber estado unidos mediante estructuras empedradas, como la construcción EC18, de planta cuadrangular, situada entre las sepulturas SP13 y SP16 (Fig. 3A).

El segundo tipo de estructura más documentado es la deposición de las urnas sobre el terreno natural, sin túmulo u otra estructura construida que las cubra. Se han recuperado 15 (DP05, SP14, SP20, DP22, DP24, DP26, SP27, DP29, DP34, SP35, DP36, DP37, DP38, DP41 y SP42), en diferente grado de conservación, dispuestas alrededor de los túmulos. Una losa de piedra cubría las urnas SP27, DP29 y DP36, elemento

\begin{tabular}{|c|c|c|c|c|c|c|c|c|}
\hline \multirow[b]{2}{*}{ Sepultura } & \multicolumn{4}{|c|}{ Características del depósito } & \multicolumn{4}{|c|}{ Restos humanos } \\
\hline & Túmulo & Urna & Ajuar & Datación C14 & NMI & Edad & Peso total $/ g$ & $\mathbf{T} /{ }^{\circ} \mathbf{C}^{*}$ \\
\hline SP01 & sí & sí & sílex & & 1 & Adulto $(>18)$ & 478,24 & $600 / 700$ \\
\hline SP02 & sí & no & - & & - & - & - & \\
\hline SP03 & sí & sí & bronce & & - & - & - & \\
\hline SP04 & sí & no & - & & - & - & - & \\
\hline DP05 & no & sí & - & & - & - & - & \\
\hline SP06 & sí & no & - & & - & - & - & \\
\hline SP07 & sí & sí & bronce & & 1 & Adulto & 38,95 & 1000 \\
\hline
\end{tabular}

(2) A cargo de la empresa SOT Prospecció.

Tab. 1 (pie en página siguiente)

Trab. Prehist., 70, N. ${ }^{\circ}$ 2, julio-diciembre 2013, pp. 295-314, ISSN: 0082-5638

doi: $10.3989 /$ tp.2013.12114 


\begin{tabular}{|c|c|c|c|c|c|c|c|c|}
\hline \multirow[b]{2}{*}{ Sepultura } & \multicolumn{4}{|c|}{ Características del depósito } & \multicolumn{4}{|c|}{ Restos humanos } \\
\hline & Túmulo & Urna & Ajuar & Datación C14 & NMI & Edad & Peso total $/ g$ & $\mathbf{T} /{ }^{\circ} \mathbf{C}^{*}$ \\
\hline SP08 & sí & sí & - & $800-500 \mathrm{BC}$ & 1 & Subadulto & 144,23 & 850 \\
\hline SP09 & sí & frag & - & & - & - & - & - \\
\hline SP10 & sí & sí & bronce & & - & - & - & - \\
\hline SP13-total & sí & frag & sílex & 400-200BC & 2 & Subadulto + Adulto & 357,59 & $\approx 800 / 300$ \\
\hline SP14 & no & sí & sílex & & 1 & $?$ & & - \\
\hline SP15 & sí & no & - & & - & - & - & - \\
\hline SP 16- total & sí & sí & bronce & $400-200 \mathrm{BC}$ & 2 & Subadulto + Adulto & 329,69 & $\approx 300 / 800$ \\
\hline SP17 & sí & frag & - & & - & - & - & - \\
\hline SP19 & sí & frag & bronce & & - & - & - & - \\
\hline SP20 & no & sí & - & & 2 & Subadultos 2-3 y 9 & 33,68 & 825 \\
\hline SP21 & sí & sí & bronce & & 1 & Adulto & 18,42 & $650 / 800$ \\
\hline DP22 & no & sí & $\begin{array}{l}\text { bronce, } \\
\text { vaso cer. }\end{array}$ & & - & - & - & - \\
\hline DP24 & no & sí & - & & - & - & - & - \\
\hline DP26 & no & sí & bronce & & - & - & - & - \\
\hline SP27 & no & sí & bronce & $500-400 \mathrm{BC}$ & 1 & Subadulto 5-7 años & 214,5 & 900 \\
\hline SP28 & sí & sí & bronce & & 1 & Adulto & 1,48 & 825 \\
\hline DP29 & no & sí & bronce & & - & - & - & - \\
\hline SP30 & sí & frag & - & & 1 & Adulto & 10,35 & 800 \\
\hline SP31 & sí & frag & $\begin{array}{l}\text { bronce, } \\
\text { sílex }\end{array}$ & & - & - & - & - \\
\hline UE10101 & & & & & 1 & Adulto & 8,12 & 825 \\
\hline SP32 & sí & no & & $900-800 \mathrm{BC}$ & 1 & Adulto & 27,42 & 850 \\
\hline SP33 & no & no & - & & 1 & Subadulto $(<20)$ & 31,92 & 825 \\
\hline DP34 & no & sí & - & & - & - & - & \\
\hline SP35 & no & sí & bronce & & 1 & Adulto & 32,02 & $850-900$ \\
\hline DP36 & no & sí & - & & - & - & - & - \\
\hline DP37 & no & sí & bronce & & - & - & - & - \\
\hline DP38 & no & sí & - & & - & - & - & - \\
\hline SP39 & sí & sí & - & & 1 & Adulto & 12,73 & 850 \\
\hline EC40 & no & no & bronce & & - & - & - & - \\
\hline DP41 & no & sí & bronce & & - & - & - & - \\
\hline SP42 & no & sí & - & & 1 & Adulto & 7,9 & 900 \\
\hline SP43 & no & no & - & & 1 & Adulto & 41,84 & $850-900$ \\
\hline UE10048 & no & no & - & & 1 & Subadulto & 93,84 & $800-825$ \\
\hline
\end{tabular}

* La calibración de la temperatura y el tiempo de duración de la cremación de huesos humanos fue obtenida en estudios previos con difracción de rayos X (drx) (Piga et al. 2009), excepto la urna 1, donde se ha estimado por coloración.

Tab. 1. Resumen de las sepulturas (SP) y otros depósitos (DP) documentados en la necrópolis del Hierro I de Sebes (Flix, Tarragona), con indicación de su contenido. NMI= Número Mínimo de Individuos; $\mathrm{T} /{ }^{\circ}=$ Temperatura de la cremación en grados centígrados; $\mathrm{UE}=$ Unidad Estratigráfica; frag= fragmento; cer.= cerámico. 

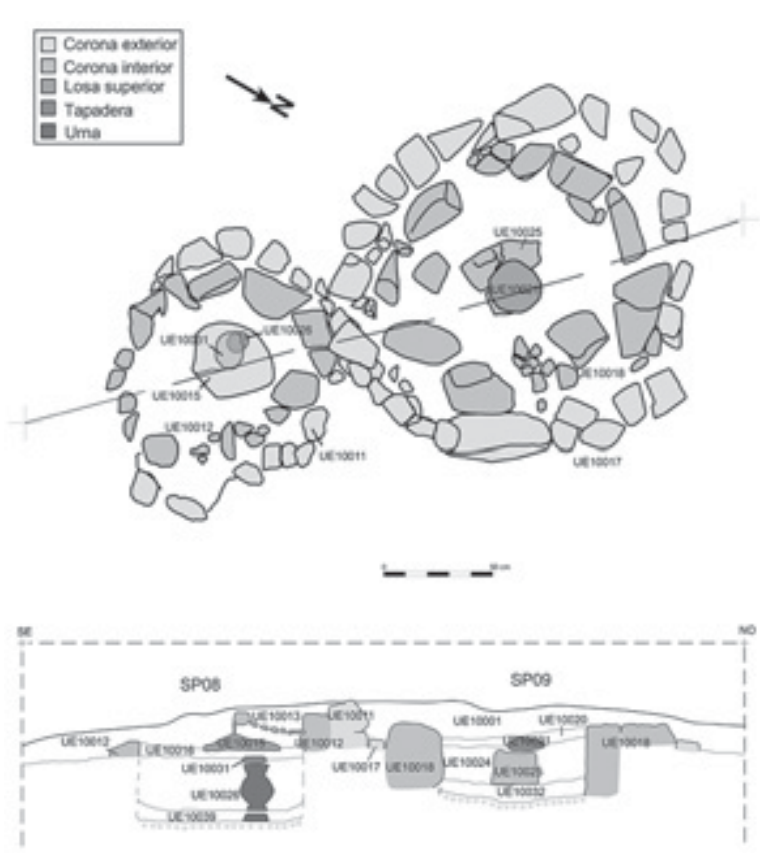

Fig. 4. Planta y secciones de las sepulturas SP08 y SP09 de la necrópolis del Hierro I de Sebes (Flix, Tarragona) (completa Belarte et al. 2012b: 97, fig. 4).

de cierre no identificado en el resto. Por lo que respecta a su contenido, en 3 urnas solo había restos óseos (SP14, SP20, SP42), en 2 los huesos estaban acompañados por objetos metálicos (SP27 y SP35), en 4 solo había metal, normalmente fragmentos de brazalete o anillas (DP26, DP29, DP37, DP41) y 5 aparecían vacías (DP05, DP24, DP34, DP36, DP38). DP22 es excepcional: tenía un pequeño vaso cerámico, una fíbula y una anilla (Fig. 5). El contenido de las urnas no parece relacionarse con la presencia o ausencia de tapadera. No se han recuperado semillas $u$ otros restos paleobotánicos tras el tamizado por flotación de la tierra procedente de las urnas.

Junto a las urnas, las acumulaciones de huesos SP33 y SP43 parecen haber sido depositados directamente sobre el terreno, tal vez envueltas en un contenedor de material perecedero.

Finalmente, las estructuras EC11 y EC12, construidas a base de piedras planas, son de forma poco definida y función desconocida (Fig. 3A). En su interior no se recuperaron materiales arqueológicos. Su cercanía y posición central en la necrópolis sugieren la posibilidad de que delimitaran dos sectores de la misma. EC40, de configuración similar, se sitúa junto a una agrupación de túmulos en el sector sur de la necrópolis. Por último, EC23, formada por dos losetas verticales fijadas con pequeñas piedras a modo de cuña, pudo haber sido un elemento señalizador.
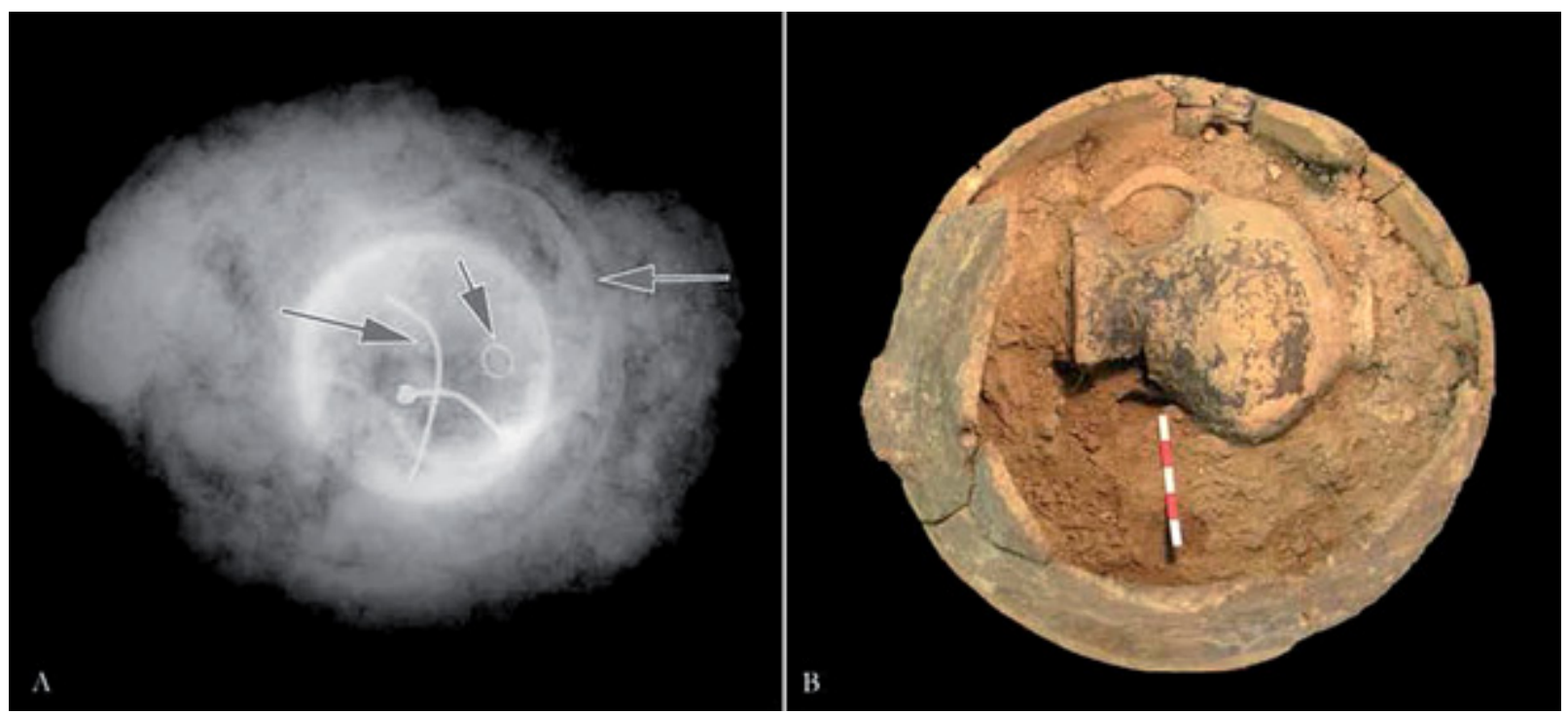

Fig. 5. Urna DP22 de la necrópolis del Hierro I de Sebes (Flix, Tarragona) depositada in situ sin relación directa con un túmulo (localizada en Fig. 3 con letra de mayor tamaño) (Belarte et al. 2012b: 99, fig. 6): A. Radiografía (Hospital Joan XXIII, Tarragona) mostrando un pequeño vaso cerámico y objetos metálicos; B. El depósito en curso de excavación.

Trab. Prehist., 70, N. ${ }^{\circ}$ 2, julio-diciembre 2013, pp. 295-314, ISSN: 0082-5638

doi: $10.3989 /$ tp. 2013.12114 


\subsection{Los materiales muebles}

La excavación de la necrópolis de Sebes ha proporcionado cerámica, metal y objetos líticos. Todos proceden de contextos funerarios claros, ya sea de enterramientos o de depósitos rituales.

Los 30 contenedores cerámicos recuperados están intactos o ligeramente fragmentados por lo que son fácilmente reconstruibles. Todos se confeccionaron a mano. En cambio, en los dos núcleos de hábitat adyacentes, sí aparece cerámica a torno. Así, en los niveles de abandono del asentamiento del Hierro I se hallaron fragmentos de ánfora fenicia procedentes del Círculo del Estrecho, mientras que en los niveles de uso del asentamiento contiguo de finales del siglo VI a.C. la cerámica ibérica a torno supera a la cerámica a mano.

Las urnas presentan tamaños y formas similares (Figs. 6 y 7): borde exvasado, cuello ligeramente estrangulado, perfil globular y fondo plano o algo umbilicado, sin carenas acentuadas. La diferencia más notable reside en la forma de la base: con el pie elevado o anular (SP21, SP27, DP29, SP31) o con el fondo plano o someramente umbilicado (SP3, SP14, SP27, SP28, SP35, DP36, DP37, DP41, SP42). Su acabado suele ser bueno. Normalmente tienen perfiles uniformes y simétricos, a menudo con las paredes delgadas, por lo que son muy frágiles. Esta característica sugiere que no son piezas domésticas reutilizadas, sino fabricadas expresamente para una función funeraria (3).

Únicamente 8 urnas están decoradas, casi siempre con motivos escasos y repetitivos, como líneas paralelas incisas poco marcadas, entre el cuello y el cuerpo (SP01, SP09, DP22, DP29, SP31 y SP35). Las SP20 y SP27 muestran líneas paralelas y triángulos mediante pequeñas incisiones, mientras SP01, SP07 y SP31 tienen un par de pequeños apéndices o botones también situados en la mitad superior del cuerpo.

La forma y decoración de los vasos propiamente funerarios (osarios) suele ser idéntica a la de los vasos de acompañamiento rituales, por lo que ambos rasgos no son discriminantes. En resumen, la homogeneidad formal de las urnas induce a pensar que estamos ante un ritual funerario bien

(3) Excepto la urna SP21, cuyo orificio postcocción en la base anular podría indicar un uso doméstico original y otro funerario posterior.
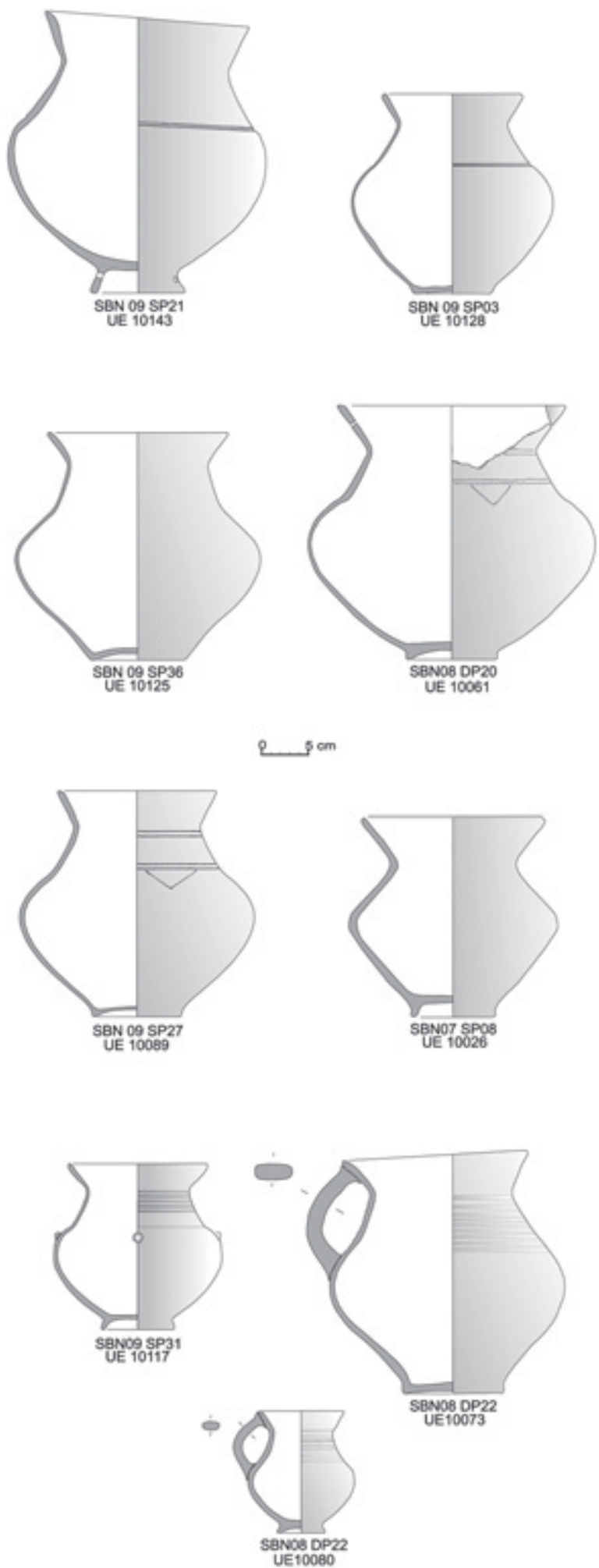

Fig. 6. Selección de urnas cerámicas procedentes de las sepulturas del Hierro I de Sebes (Flix, Tarragona). 


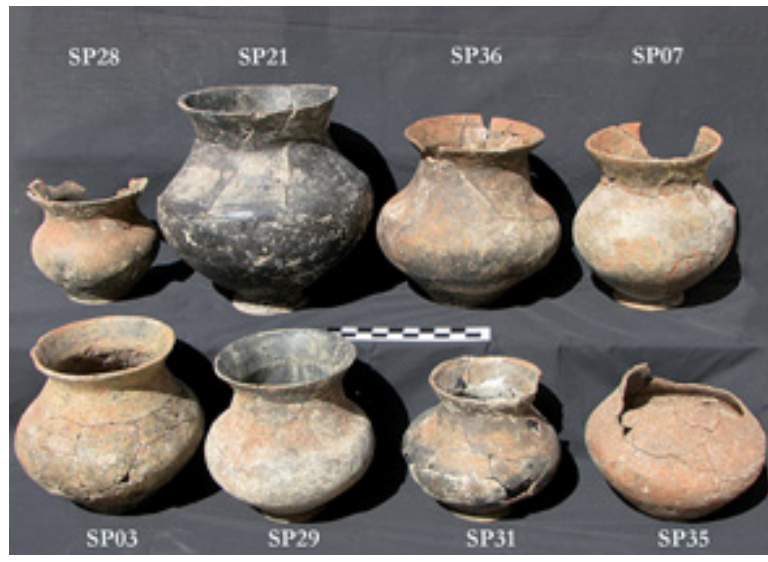

Fig. 7. Urnas cerámicas, procedentes de las sepulturas del Hierro I de Sebes (Flix, Tarragona), una vez excavadas y reconstruidas.

establecido e uniforme y que la duración del cementerio fue relativamente breve.

Las características descritas de las urnas de Sebes son asimilables a las de las necrópolis cercanas de Santa Madrona (Belarte y Noguera 2007), el Calvari del Molar (Vilaseca 1943; Castro 1994), Coll del Moro (Rafel 1991) o la Tosseta de Guiamets (Vilaseca 1956). Las fases de utilización más importantes de todas ellas se centran entre el 800 y el 600 a.C. Así, las urnas sin pie y con una forma caracterizada por un perfil bajo se datan en torno a la segunda mitad del siglo VIII a.C. en la necrópolis del Coll del Moro (Rafel 1991: 65-67). Muchas de las urnas del Calvari con este perfil (Vilaseca 1943) se fechan en pleno siglo VIII a.C. (Ruiz Zapatero 1985: 164), mientras que las urnas con perfil globular, borde exvasado, cuello estrangulado y base umbilicada son omnipresentes en todas las necrópolis citadas durante el siglo VII a.C. Incluso los escasos contenedores cerámicos de Sebes que se escapan de la caracterización general se documentan en las necrópolis de la zona. Este es el caso de la urna de la sepultura SP08, con un perfil marcadamente bitroncocónico acentuado por un gran borde exvasado y cuello estrangulado. Su pie elevado y muy diferenciado corresponde a un momento avanzado de pleno siglo VII a.C. (Castro 1994: 95; Rafel 1991: 9-10) e incluso inicios del siglo VI a.C. (Barrachina et al. 2010: 345). Un segundo ejemplo es el depósito DP22, constituido por una urna con asa que contenía, junto a objetos metálicos, un segundo envase de forma idéntica pero de menor tamaño (Fig. 5B). Son las dos únicas urnas con asa de toda la necrópolis y son similares a otras del Coll del Moro (Rafel 1991: 10 y 21), Santa Madrona (Belarte y Noguera 2007: 46) o el Calvari (Vilaseca 1943: 29, lám. VII, fig. 12; Castro 1994: 87).

Los contados objetos metálicos de la necrópolis de Sebes son siempre de bronce. La mayoría están deformados por las altas temperaturas a las que fueron sometidos y, en ocasiones, su forma original casi no se puede identificar. Entre los materiales procedentes de sepulturas o depósitos rituales destacamos una anilla y una fíbula de doble resorte (DP22), habitual en las necrópolis contemporáneas del curso inferior del río Ebro, como el Calvari y la Tosseta, y característica de los siglos VII y VI a.C. (Navarro 1970: 28-30; Rafel et al. 2008: 255). Añadimos el conjunto de 45 fragmentos de la sepultura SP19 entre los que destaca un puente de fíbula de resorte bilateral del siglo VI a.C. (Navarro 1970: 55-56), tipo que está presente en la vecina necrópolis de Santa Madrona (Belarte y Noguera 2007: 54). En la sepultura SP31 se hallaron 12 anillas y 3 eslabones de una pequeña cadena (Fig. 8 sup.), también elementos habituales en las necrópolis de la época, pero poco significativos a efectos cronológicos. En la sepultura SP28 se recuperaron dos brazaletes, una anilla de sección ovalada, un botón hemisférico y un conjunto de eslabones de cadenitas (Fig. 8 inf.).

Ahora bien, la mayoría de los fragmentos corresponden a brazaletes de sección rectangular, algunos decorados con tres estrías paralelas incisas en su extremo distal, así como a piezas de sección plano-convexa (Fig. 9). Son también objetos muy abundantes en las necrópolis del Ebro, como las de Santa Madrona (Belarte y Noguera 2007: 53), el Calvari (Vilaseca 1943: 18-20; Castro 1994: 106) y el Coll del Moro (Rafel 1991: 118). Estos brazaletes se fechan entre finales de siglo VIII e inicios de siglo VI a.C. (Ruiz Zapatero 1985: 965), y más concretamente en el Coll del Moro entre la segunda mitad de siglo VIII y finales de siglo VI a.C. (Rafel 1991: 125).

En definitiva, se trata de un conjunto de bronces muy homogéneo y con poca variedad tipológica. Los objetos de ornamentación personal o vinculados a la vestimenta son casi exclusivos, 


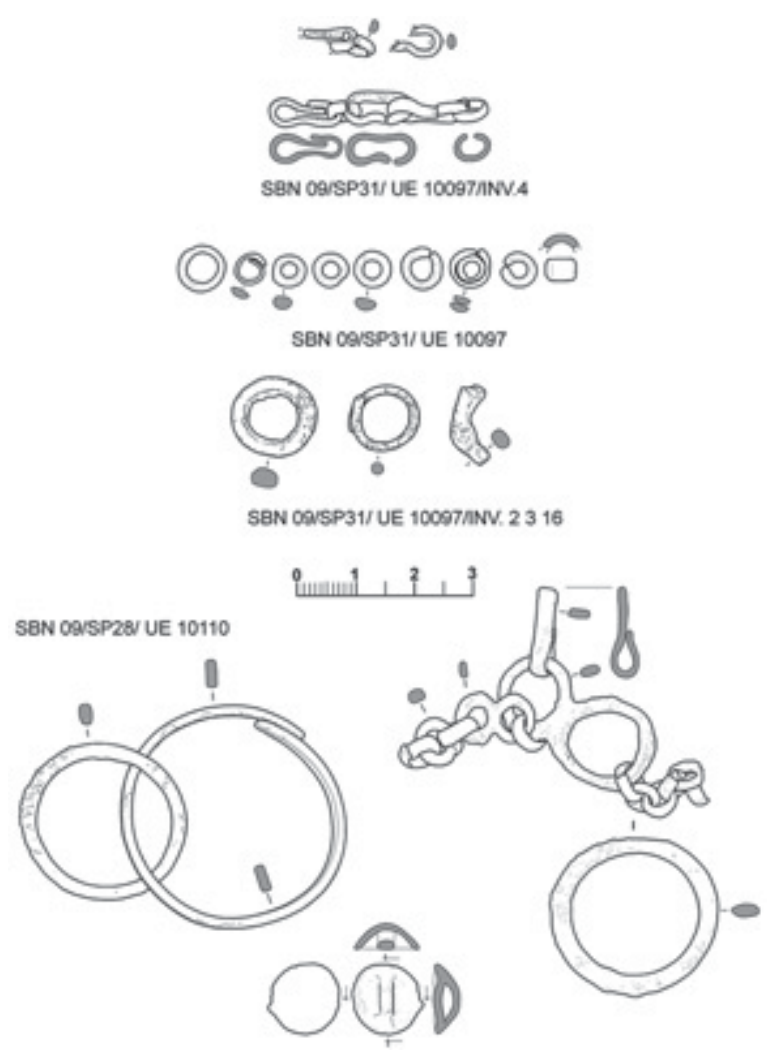

Fig. 8. Selección de objetos de bronce del Hierro I de Sebes (Flix, Tarragona) (dibujos Ramón Álvarez): eslabones y anillas de la sepultura SP31 (sup.); brazaletes, eslabones, botón y anilla de la sepultura SP28 (inf.).

mientras faltan los objetos de tocador, las herramientas o el armamento.

Los materiales líticos recuperados en la necrópolis son las tapaderas de los túmulos y de las urnas y los restos de sílex. Las tapaderas se realizaron con lajas de piedra calcárea local, de unos $5 \mathrm{~cm}$ de grosor. A partir de su forma y función se diferencian claramente dos tipos. El primero comprende lajas destinadas a cubrir el orificio destinado a la urna o loculus, habitualmente documentado en tumbas con túmulo. Apenas están trabajadas por lo que su forma es muy irregular. Sus dimensiones son siempre mayores que las del segundo tipo: las tapaderas destinadas a cerrar la boca de la urna. Estas, mucho más trabajadas, tienden a ser aproximadamente circulares y con un diámetro ligeramente superior al de la boca de la urna.

Finalmente, en ocasiones se han recogido fragmentos de sílex, bronces y huesos en el relleno

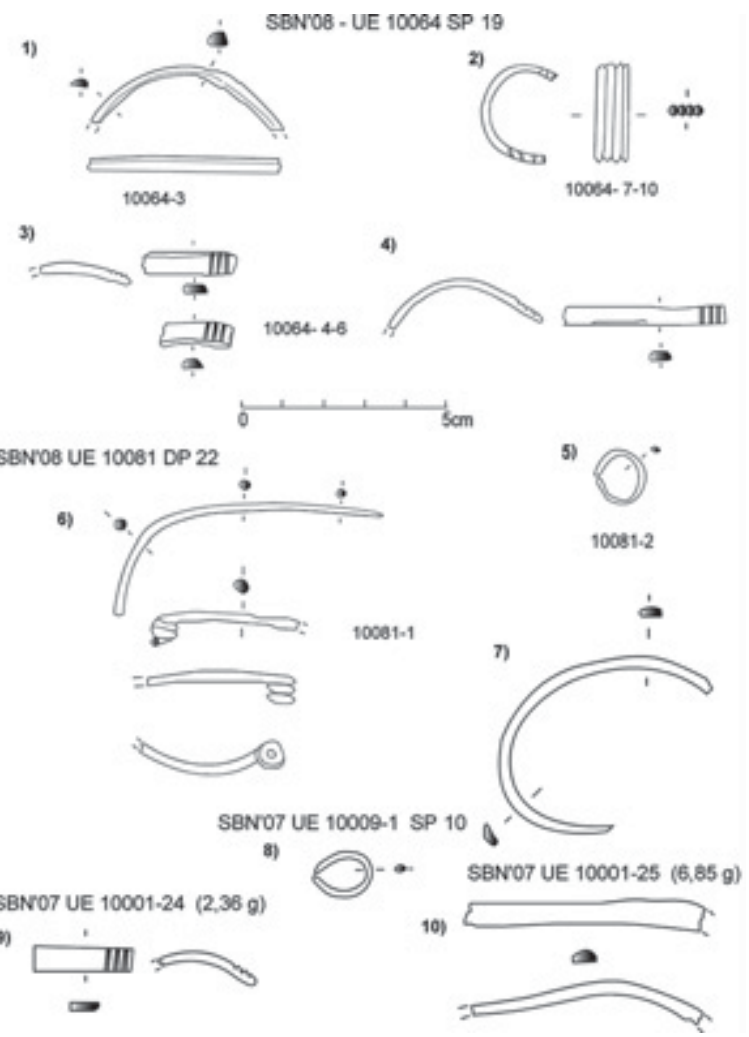

Fig. 9. Selección de brazaletes de bronce, procedentes de las sepulturas del Hierro I de Sebes (Flix, Tarragona), algunos decorados con tres estrías paralelas incisas en su extremo distal, y otros objetos. 1 a 4: Brazaletes de SP19; 5 a 7: objetos de bronce de DP22 (5: anilla, 5: fíbula, 7: brazalete); 8: anilla de la SP10; 9 y 10: brazaletes del nivel superficial.

de pequeñas piedras que cubre la tumba. Parece como si, una vez enterrada la urna, se hubiera realizado un ritual específico que resultó en la deposición de estos elementos. Los fragmentos de sílex nunca están trabajados.

La cronología que se desprende del estudio tipológico de las urnas y de los metales apunta al siglo VIII a.C. como posible inicio de la necrópolis, pero creemos más probable que se centre en pleno siglo VII y la primera mitad del siglo VI a.C. Esta cronología es contemporánea al asentamiento del Hierro I de Sebes, donde en los niveles de derrumbe de las casas se recuperaron fragmentos de ánfora fenicia. La ausencia en la necrópolis de esta cerámica de importación no debe sorprendernos, ya que a excepción del Coll del Moro, tampoco aparece en las necrópo- 


\begin{tabular}{|c|c|c|c|c|c|c|c|c|c|c|c|}
\hline Análisis & Objeto & Contexto & $\mathrm{Fe}$ & $\mathrm{Ni}$ & $\mathbf{C u}$ & $\mathbf{Z n}$ & As & Ag & Sn & Sb & $\mathbf{P b}$ \\
\hline PA20493 & Brazalete & SBN08 - SP19 & nd & nd & 88,5 & nd & nd & nd & 8,91 & nd & 2,56 \\
\hline PA20494 & Brazalete & SBN08 - UE10064 - SP19 & nd & nd & 85,6 & nd & nd & nd & 9,57 & nd & 4,78 \\
\hline PA20495 & Cuenta & SBN09 - UE10097 - SP31 & 0,27 & nd & 81,5 & nd & nd & nd & 17,4 & nd & 0,84 \\
\hline PA20496 & Brazalete & SBN07 - UE10001 & nd & nd & 87,1 & nd & nd & nd & 11,2 & nd & 1,65 \\
\hline
\end{tabular}

Tab. 2. Análisis mediante Fluorescencia de rayos X. Los análisis se expresan como porcentaje en peso de cada uno de los elementos detectados (nd= no detectado). El límite de detección de plata (Ag) y antimonio (Sb) es $0,20 \%$; para el resto de elementos se sitúa en el $0,02 \%$.

lis contemporáneas de Castellets de Mequinenza, Santa Madrona, la Tosseta, Castellons de Flix o el Calvari, mientras que en los asentamientos correspondientes a las dos últimas es una cerámica bien documentada.

\subsection{Análisis arqueometalúrgicos}

Una muestra de 3 fragmentos de brazalete y una cuenta ha sido estudiada en colaboración con el proyecto coordinado "El factor minero en el desarrollo histórico de Cataluña meridional: de la Prehistoria a época medieval", HAR201021105-C02-00 (4). Para el análisis elemental se ha utilizado el espectrómetro portátil de fluorescencia de rayos X INNOV-X Alpha (pFRX) del Museo Arqueológico Nacional (Madrid). Los resultados de la tabla 2 señalan que las 4 piezas son bronces y dos de ellas entrarían en la categoría de bronces plomados (más de $2 \%$ de plomo). No se han detectado impurezas de otros elementos.

Se seleccionaron un bronce plomado y otro binario para su análisis de isótopos de plomo mediante Espectrometría de Masas con fuente de Plasma de Acoplamiento Inductivo (MC-ICPMS) en el Laboratorio de Geocronología de la Universidad del País Vasco. Montero-Ruiz et al. (2012) informan sobre las condiciones de análisis y los datos geológicos de referencia. Según los resultados (Tab. 3, Fig. 10) la procedencia del metal empleado es similar a la del usado en el poblado y necrópolis de El Calvari y en otros

(4) Agradecemos a Nuria Rafel y a Ignacio Montero, investigadores responsables de cada subproyecto, las facilidades dadas para el estudio de estos materiales, así como la información de otros resultados que se manejan en este artículo.

\begin{tabular}{|c|c|c|c|c|c|}
\hline Inventario & $\begin{array}{l}208 \mathrm{~Pb} / \\
206 \mathrm{~Pb}\end{array}$ & $\begin{array}{l}207 \mathrm{~Pb} / \\
206 \mathrm{~Pb}\end{array}$ & $\begin{array}{l}206 \mathrm{~Pb} / \\
204 \mathrm{~Pb}\end{array}$ & $\begin{array}{l}207 \mathrm{~Pb} / \\
204 \mathrm{~Pb}\end{array}$ & $\begin{array}{l}208 \mathrm{~Pb} / \\
204 \mathrm{~Pb}\end{array}$ \\
\hline PA20494 & 2,1052 & 0,8568 & 18,253 & 15,638 & 38,427 \\
\hline PA20496 & 2,1031 & 0,8557 & 18,291 & 15,652 & 38,467 \\
\hline
\end{tabular}

Tab. 3. Resultados de los análisis de isótopos de plomo de dos brazaletes de bronce plomado y binario de la necrópolis del Hierro I de Sebes (Flix, Tarragona) (inventario en Tab. 2).

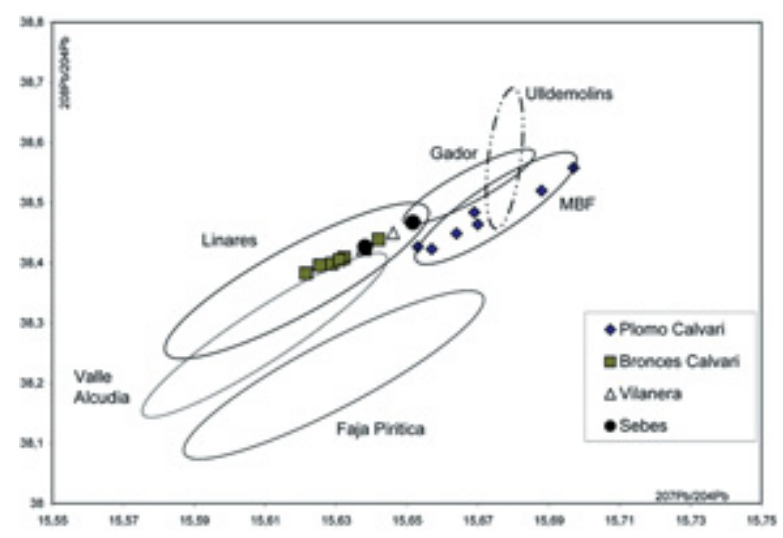

Fig. 10. Representación de los resultados de los análisis de isótopos de plomo de los brazaletes de Sebes (Flix, Tarragona) (véase Tab. 3) en relación a los materiales de otros yacimientos del I Hierro del noreste de la Península Ibérica y mineralizaciones de la misma.

yacimientos del noreste de la Península Ibérica en este periodo. Este metal pudo llegar a la región en forma de lingotes de cobre o cobre-plomo muy probablemente desde el área de Linares (Montero-Ruiz et al. 2012). Los datos aportados por la necrópolis de Sebes parecen confirmar la importancia del metal en las redes comerciales entre el Bajo Ebro y el área de Linares para la obtención de cobre durante el siglo VII e inicios del VI a.C. 


\subsection{Estudio bioantropológico}

Las urnas y las acumulaciones de huesos de la necrópolis de Sebes fueron extraídas en bloque y excavadas en el laboratorio del ICAC. Previamente fueron radiografiadas en el Hospital Joan XXIII de Tarragona (5) (Fig. 5A). Además a la sepultura SP27 se le realizó una tomografía en el Hospital Universitari del Sagrat Cor de Barcelona (6) (Fig. 11). Con ello se pretendía identificar la disposición de los huesos y de los posibles objetos metálicos u otros elementos del ajuar funerario en el interior de las urnas. Los restos óseos, una vez extraídos, fueron objeto de un análisis antropológico morfológico y fisicoquímico.

Se han identificado un mínimo de 21 individuos procedentes de 18 urnas o conjuntos óseos. Según el análisis morfológico (Tab. 1), había 12 adultos, 8 subadultos (uno entre 2 y 3 años de edad, uno entre 5 y 7 años y el resto entre los 9 y

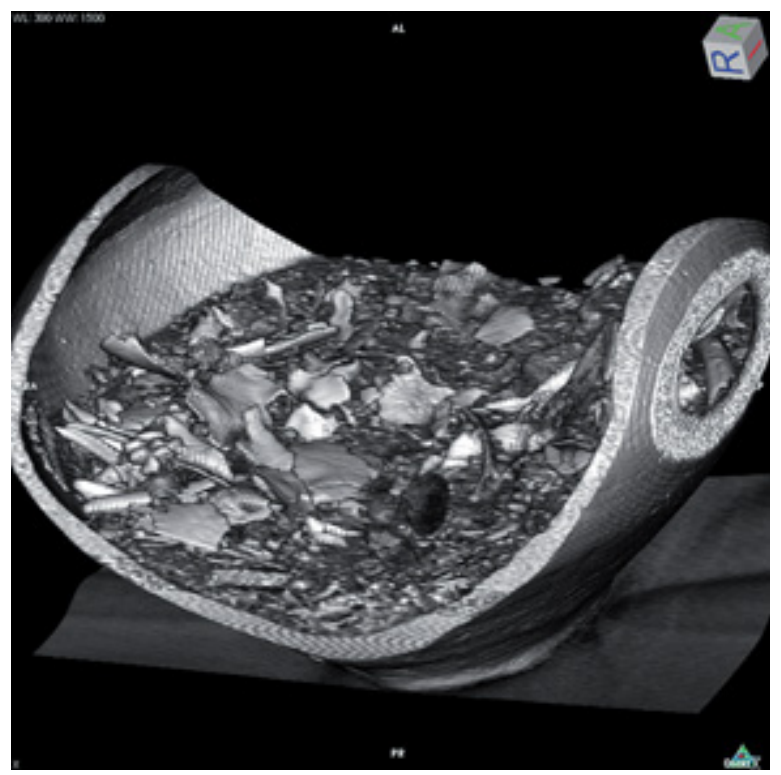

Fig. 11. Tomografía de la urna SP27 de la necrópolis del Hierro I de Sebes (Flix, Tarragona), realizada en el Hospital Universitari del Sagrat Cor de Barcelona. Tamaño de la pieza: $25 \mathrm{~cm}$ de diámetro máximo.

(5) A cargo del Dr. Emili Provinciale, mediante un convenio de colaboración entre el ICAC y el Hospital Joan XXIII de Tarragona.

(6) A cargo del Dr. Albert Isidro, miembro del GROB (Universidad Autónoma de Barcelona). los 20 años) y uno indeterminado. El sexo solo ha podido determinarse en 3 individuos masculinos. Los huesos aparecen muy fragmentados y con coloración blanquecina (Fig. 12). Según el análisis fisicoquímico (difracción de rayos $\mathrm{X}$ ) la mayoría fueron expuestos a temperaturas homogéneas y prolongadas entre $825^{\circ}$ y $1000^{\circ}$ ) (Piga et al. 2009). Excepcionalmente, en dos casos los huesos habían sido sometidos a una combustión baja (entre $200^{\circ}$ y $300^{\circ}$ ), por lo que aparecen ennegrecidos y sin fracturas transversales. Esta combustión a baja temperatura parece relacionarse exclusivamente con individuos adultos.

Las sepulturas eran individuales, salvo SP13, SP16 y SP20, que eran dobles con ciertas peculiaridades. SP13 es una estructura tumular sin urna en cuyo interior se depositaron los restos de, al menos, dos individuos. SP16 es un túmulo que contenía una urna cerámica a modo de osario. En cada una de las sepulturas se introdujeron un individuo adulto y uno joven que habría sufrido una combustión más intensa. Es posible que la presencia de dos individuos indique una reutilización. Ello parece evidente en la sepultura SP16, que no estaba intacta. Faltaba la losa de cubierta de la urna y esta apareció fragmentada. Una parte de los huesos fue recuperada en su interior, mientras el resto apareció disperso en el interior del túmulo. El estudio antropológico de la SP13 sugiere que la presencia de dos individuos podría indicar bien una recogida poco cuidadosa en la pira funeraria o bien la reutilización de

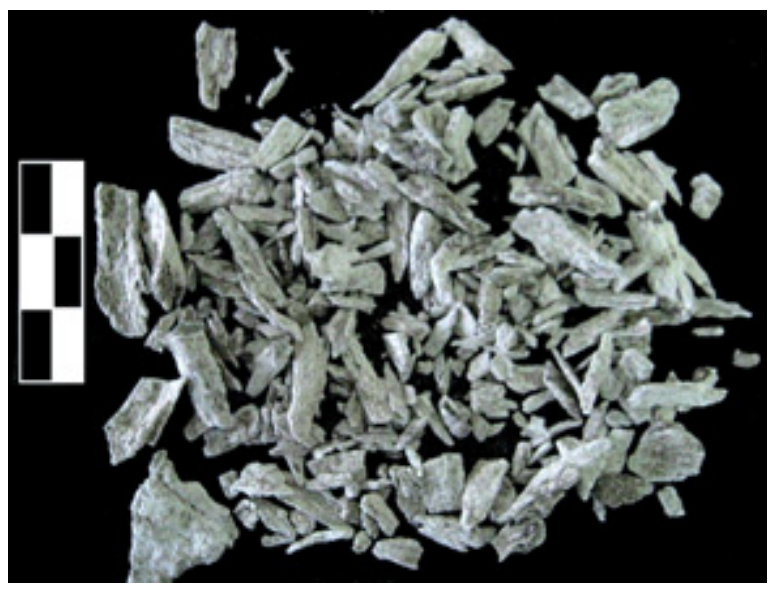

Fig. 12. Detalle de los restos óseos cremados recuperados en la UE 10120 (sepultura SP33) de la necrópolis del Hierro I de Sebes (Flix, Tarragona). 
una estructura tumular no completamente limpia de los restos de las deposiciones anteriores. En el exterior del túmulo (UE 10048) la concentración de huesos asignada a un individuo joven o adulto, quizás procedente de la limpieza de la SP13, podría confirmar la hipótesis de la reutilización. En su contra está la hilera de pequeñas piedras existente en la parte superior del relleno del túmulo. Esta posible compartimentación podría haber indicado en superficie los espacios correspondientes a los dos individuos depositados. La sepultura SP20 (urna sin túmulo) contenía dos subadultos.

El número de individuos incorporados a la SP33 es dudoso. Como en las anteriores se han detectado coloraciones diferentes en los restos óseos: mientras la mayoría son blancos, algunos tienen un color azul oscuro. Esto podría indicar o bien que la cremación del cuerpo fue desigual o bien que en la misma urna se recogieron y depositaron restos procedentes de diferentes cremaciones, aunque, a nivel esquelético, solo se pudo identificar un individuo.

El volumen de huesos conservados en cada sepultura es muy variable: entre $1,48 \mathrm{~g}$ en la sepultura SP28 y 478,24 g en la SP01, siendo en general inferior a los $100 \mathrm{~g}$. Hay cierta variedad en los huesos representados. Ello indica que solo una minoría era recogida de la pira funeraria para ser enterrada en la necrópolis. Faltaba, al parecer, un patrón que priorizara el tipo y número de huesos a enterrar. La presencia de más de un individuo en una misma sepultura con desigual representación por peso y número de restos sugiere que la recogida pudo ser aleatoria, al menos en algunos casos. En este mismo proceso se debían recuperar también algunos objetos metálicos (brazaletes, anillos, fíbulas,...) que habían sido quemados junto con el difunto, ya que presentan indicios de haber sufrido una combustión a altas temperaturas.

\subsection{Datación radiocarbónica}

Paralelamente al estudio de los restos óseos, se seleccionaron 6 muestras de hueso quemado para datar por C14. Procedían de diferentes contextos: urnas totalmente selladas (SP08 y SP27), acumulación de huesos calcinados en el interior de un túmulo con urna (SP16 y SP32) o sin ella (SP13)

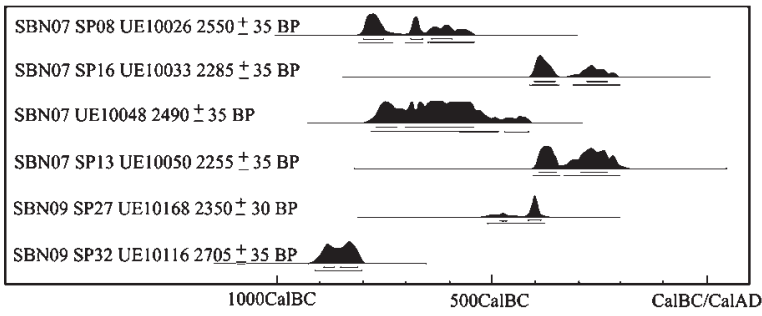

Fig. 13. Curvas de calibración de las dataciones radiocarbónicas realizadas en el Poznan Radiocarbon Laboratory (Polonia).

y huesos recuperados entre sepulturas (UE 10048) (Tab. 1). Las dataciones calibradas obtenidas oscilan entre los siglos VIII y III cal BC (Fig. 13) (7). Desgraciadamente, la mayor o menor antigüedad de las fechas no ha podido relacionarse con las diferencias en los tipos de enterramiento o en su estado de conservación. Las tres dataciones más antiguas pertenecen a una acumulación de huesos entre túmulos (UE 10048: 800-400 cal BC) y a dos urnas en túmulo: la SP08 (800-500 cal BC) estaba perfectamente sellada, mientras en la SP32 (900-800 cal BC) había entrado tierra tras su deposición. Las fechas más recientes, y que se alejan de la información sugerida por los materiales cerámicos, se han obtenido de la segunda urna sellada SP27 (500-400 cal BC), del enterramiento tumular en urna SP16 (400-200 cal BC) y del túmulo sin urna SP13 (400-200 cal BC). Como ya hemos descrito en el apartado anterior, en dichos túmulos se depositaron los restos de más de un individuo y, probablemente, hubo reutilización. En cambio, la SP27 era una urna sellada, por lo que debemos preguntarnos si realmente este enterramiento es más tardío o si la fecha obtenida debe atribuirse a un problema del método C14 para este período.

\section{DISCUSIÓN}

Nos hallamos ante una necrópolis completamente excavada en extensión, relativamente bien conservada, y con una zona de hábitat conocida y

(7) Las dataciones fueron calibradas mediante dos versiones del programa OxCal (Bronk Ramsey 2001, 2009).

Trab. Prehist., 70, N. ${ }^{\text {2 }}$ 2, julio-diciembre 2013, pp. 295-314, ISSN: 0082-5638

doi: $10.3989 /$ tp.2013.12114 
en curso de excavación por nuestro equipo. Como viene siendo habitual en los recientes proyectos de investigación centrados en las necrópolis de cremación, el recurso a múltiples técnicas de análisis (prospección geofísica, estudio antropológico, radiografías, análisis físico-químicos, datación por $\mathrm{C} 14$, etc.) intenta dar un paso adelante y romper con el inmovilismo que parecía haberse instalado en el estudio del tema.

A pesar de ello, en el momento de su interpretación, en ocasiones los resultados generan más interrogantes o dudas que posibles respuestas.

El principal problema que se nos plantea es precisar la cronología de la necrópolis, no solo cuándo y durante cuánto tiempo fue utilizada, sino también la secuencia de construcción de los enterramientos o las diversas reutilizaciones de las sepulturas, si es que se produjeron. Como se ha expuesto ya, carecemos de una estratigrafía horizontal. En muy pocas ocasiones hemos documentado relaciones estratigráficas entre los enterramientos. En general, los indicios de reutilización son ambiguos, poco seguros: podrían responder a nuevos enterramientos o a remociones posteriores o expolios.

Por este motivo, desde un inicio nos planteamos la realización de dataciones radiocarbónicas para complementar la información procedente del estudio de los materiales (sobre todo cuando las urnas no estaban asociadas a restos óseos), a pesar de ser conscientes de los problemas y limitaciones del método para el período estudiado (Rafel y Armada 2008: 154-157). Como es habitual y ya hemos mencionado, las dataciones radiocarbónicas proporcionan unas horquillas demasiado amplias e incluso, en ocasiones, se adentran en el período ibérico.

Recordemos que recientemente hemos identificado en Sebes un hábitat de la segunda mitad del siglo VI a.C. (Belarte et al. 2012a), es decir, inmediatamente posterior al del Hierro I (e incluso de mayor superficie), sin que de momento se haya localizado una necrópolis de esta cronología. Es lícito preguntarse si la población del siglo VI a.C. continuaba enterrándose en la necrópolis del Hierro I (8). A pesar de los problemas planteados por los análisis de $\mathrm{C} 14$,

(8) En la necrópolis inédita dels Castellons de Flix, situada a $3,7 \mathrm{~km}$ y excavada por un aficionado local, se documentan urnas a torno del Ibérico Antiguo. no podemos dejar de resaltar que las dataciones realizadas sobre huesos recogidos en los espacios entre túmulos han resultado tardías, aunque tal vez en este caso demasiado, dentro del Ibérico Pleno. En consecuencia, nos preguntamos si, aunque el C14 no sea válido en este período como método de datación absoluta, tal vez sí lo sea como método de datación relativa, y los análisis de radiocarbono realmente nos estén indicando la reutilización de la necrópolis durante el Ibérico Antiguo. La cuestión queda abierta.

En definitiva, la datación del período de utilización de la necrópolis se ha vuelto a basar en el estudio tipológico de los materiales muebles y en su comparación con los de otras necrópolis. Las piezas de Sebes guardan estrechas similitudes con las del siglo VII e inicios del siglo VI a.C. de las cercanas necrópolis de Santa Madrona, Llardecans, Castellons, el Calvari, Castellets, la Tosseta y Coll del Moro. Proponemos también esa datación para la de Sebes, donde está en consonancia con la presencia de ánforas fenicias en el asentamiento del Hierro I.

El propio ritual funerario de cremación es otro de los aspectos que dificulta el análisis de las necrópolis. Recordemos que, pese al uso de prospección geofísica, hasta el momento no hemos podido localizar la pira funeraria o ustrinum, por lo que el estudio se inicia cuando las cremaciones se han depositado ya, generalmente, en el interior de urnas. Sin ninguna duda estas deposiciones secundarias fueron seleccionadas, ya que el número de huesos quemados es muy reducido y varía mucho entre los enterramientos. Además, los huesos largos y fragmentos craneales que, en principio, deberían aparecer más por su tamaño y grosor, suelen estar poco representados. Junto a ellos se depositaron objetos de bronce, integrantes de la indumentaria personal (botones, fíbulas, brazaletes...), lógicamente también quemados y deformados por el fuego. Estos complementos metálicos normalmente se encuentran en el interior de las urnas, pero a veces se recuperan en el exterior. Probablemente los huesos se guardaban en algún hatillo realizado con materiales de difícil conservación, ya que durante la micro excavación de las urnas en ocasiones se han detectado concentraciones óseas.

Casi la totalidad de los enterramientos se depositaron en el interior de urnas, ya sea bajo túmulo o aisladas, pero también hemos identificado huesos directamente en el suelo, seguramente en un loculus irreconocible por la composición geo- 
lógica del terreno, y tal vez contenidos igualmente en un hatillo o recipiente de material perecedero.

Una vez depositada la urna con los huesos en su interior, el conjunto solía cubrirse con una tapadera de piedra calcárea y con una segunda loseta cuando el enterramiento se introducía en un túmulo circular. Finalmente el interior del túmulo se rellenaba con un encachado de piedras (Fig. 4). A veces, durante su excavación se han recuperado fragmentos de talla de sílex, de cerámica e incluso huesos, sugiriendo la práctica de algún tipo de ofrenda relacionada con la comida o bebida en los momentos finales del ritual.

Dentro de la homogeneidad del ritual, se documentan comportamientos específicos de difícil comprensión. Por ejemplo, los bordes de algunos envases cerámicos pueden presentar una fractura intencional y hay un caso de subdivisión del túmulo con una hilada de piedras. Otro aspecto de interpretación compleja son las acumulaciones de huesos en el exterior de los túmulos. Podría pensarse que proceden de enterramientos desplazados de su posición original, pero su posición estratigráfica y el que las deposiciones óseas sin urna sean habituales, tanto en esta como en otras necrópolis, nos induce a considerarlos enterramientos realizados con posterioridad a los de los túmulos, como ya hemos señalado.

Finalmente, nos referimos a la identificación de túmulos y urnas sin enterramientos. En este caso excluimos cualquier posibilidad de remoción posterior, ya que en ocasiones se localizan bajo estratos arqueológicos inalterados. Se podría plantear que las urnas aisladas sin depósito de huesos fueran vasos de ofrendas relacionados con enterramientos cercanos. La interpretación de las construcciones tumulares sin enterramiento es más difícil. Se han conectado con estructuras conmemorativas o cenotafios en las necrópolis cercanas donde se ha documentado, como en el Coll del Moro (Rafel y Hernández 1992: 53), Castellets (Royo 1994-96: 100-101) o Santa Madrona (Belarte y Noguera 2007: 33).

Generalmente se utiliza la riqueza de los ajuares como indicador de diferenciación social (Ruiz Zapatero 2001: 257-258, 2004: 294) a pesar de las dificultades que ello implica (9). Desde el punto

(9) Desconocemos el valor específico de los objetos en las sociedades protohistóricas e, incluso, algunos investigadores advierten que los ajuares funerarios y la posición social en vida de los individuos pueden estar desconectados entre sí (Parker Pearson 1999: 7). de vista del análisis social, la necrópolis de Sebes no muestra indicios de diferencias significativas, ya que los restos materiales son homogéneos. Estamos más bien ante ajuares 'pobres', con urnas similares y pocos objetos de bronce. No obstante, la reciente constatación del uso de cobre importado para la elaboración de objetos de bronce da una nueva significación a la presencia de metales, y sugiere que los individuos enterrados en las pocas tumbas que los tienen tal vez tenían un acceso preferente a las rutas comerciales del metal. También se ha identificado un ritual de enterramiento homogéneo para todos los grupos de edad sin tumbas que destaquen por su mayor tamaño o esfuerzo constructivo.

Ahora bien, según el análisis espacial de la distribución de los enterramientos, hay estructuras de piedra que dividen claramente el espacio funerario en dos grandes agrupaciones. No tenemos ningún indicio para suponer que las dos áreas de enterramiento respondan a criterios cronológicos sino más bien a factores sociales de difícil caracterización (familia, linaje, procedencia, etc.). En cada área de enterramiento en torno a los túmulos circulares planos se sitúan las urnas aisladas, con o sin restos óseos. En principio la distribución periférica de las urnas induce a pensar en una cierta posterioridad de las mismas y en que podamos estar ante enterramientos y ofrendas a cargo, quizás, de individuos con una relación de parentesco o dependencia. Como el análisis espacial de las estructuras funerarias de una necrópolis solo puede realizarse sobre yacimientos totalmente excavados, llamamos la atención sobre las que cuentan con un modelo similar de distribución, por ejemplo, el bipartito de la cercana necrópolis de Santa Madrona (Belarte y Noguera 2007: 77) o la de Sant Joaquim de la Menarella del Forcall (Castellón), cuyas estructuras mantienen una evidente simetría espacial (Barrachina et al. 2010: 343). En necrópolis de mayores dimensiones como Roques de Sant Formatge (Pita y Díez Coronel 1968), Castellets de Mequinenza (Royo 1994-1996) o Coll del Moro de Gandesa (Rafel 1989) existen diferentes sectores funerarios separados entre sí, que han sido relacionados con diferentes grupos familiares (Ruiz Zapatero 2004: 311).

Finalmente, al intentar extrapolar la información procedente de la necrópolis a la zona excavada del hábitat, tampoco vemos ni indicios de 
diferenciación social (10), ni la subdivisión en dos grandes grupos documentada en la necrópolis. Ninguna de las casas excavadas hasta ahora (Belarte y Noguera 2008) evidencia los indicadores habituales para detectar diferencias sociales, como la mayor capacidad de almacenaje o la mayor cantidad y diversidad de equipamientos domésticos o de elementos decorativos, entre otros (Ruiz Zapatero 2004: 297). Una posible excepción es un edificio situado en la parte superior de la colina, aún en curso de estudio. Contenía la mayor concentración de molinos del asentamiento, lo que puede ser expresivo tanto del control de ciertas actividades económicas por un grupo familiar, como del carácter colectivo de algunas tareas.

Llegados a este punto, y a pesar de la dificultad inherente a calcular la población que vivió y se enterró en Sebes, pensamos que un estudio demográfico, aunque sea muy aproximado, nos puede aportar nuevas perspectivas de análisis. En primer lugar, creemos que la necrópolis de Sebes no acoge diversas comunidades dispersas, sino únicamente a los individuos del hábitat contiguo. De hecho, en el tramo de río de apenas $10 \mathrm{~km}$ entre Flix y Riba-roja d'Ebre, conocemos la situación de tres necrópolis y de sus respectivas zonas de hábitat, lo que sugiere que cada asentamiento disponía de su propio cementerio. En segundo lugar, los análisis antropológicos sugieren que se entierran, si no todos, gran parte de los grupos de edad de la población, incluyendo a los infantiles. En tercer lugar, creemos que tanto el asentamiento como la necrópolis perduran un centenar de años (aproximadamente 650-550 a.C.), es decir durante unas cuatro generaciones de individuos. Finalmente, el número aproximado (11) de recintos de habitación de la ocupación del Hierro I se ha calculado entre 20 y 30 , proponiéndose una población de entre 80 y 150 individuos (Belarte y Noguera 2008: 133). Probablemente la cifra real esté muy por debajo del centenar de personas, pero aún así en la necrópolis solo se ha recuperado una veintena de individuos. Es evidente

(10) Conviene mencionar que carecemos de evidencias arqueológicas significativas por el abandono paulatino del hábitat del Hierro I que nos ha privado de grandes conjuntos de materiales muebles y por la importante erosión que han sufrido las estructuras constructivas.

(11) Se ha excavado más del $75 \%$ de la superficie total, estimada en unos $1.200 \mathrm{~m}^{2}$, pero la erosión ha destruido la práctica totalidad de la vertiente suroeste. que la tasa de mortalidad de una población de 80 individuos durante 100 años debería ser muy superior. Además, si consideramos la creación de un nuevo asentamiento contiguo, de nueva planta y de mayores dimensiones, en la segunda mitad del siglo VI a.C., tendremos que concluir que la población de Sebes experimentó un rápido crecimiento demográfico. Caben tres alternativas para resolver esta incongruencia: que el período de ocupación del asentamiento y de la necrópolis fuera muy reducido (apenas 25 o 50 años), que la necrópolis de Sebes no fuera la única zona de enterramiento del asentamiento o que no todos los individuos de la comunidad se enterraran en ella. No podemos descartar ninguna de las tres o incluso su combinación.

La necrópolis de Sebes se enmarca en el contacto entre las necrópolis de la zona del SegreCinca, las del Bajo Aragón-Terra Alta y las del curso inferior del Ebro-Priorat, gracias al eje de comunicaciones Lérida -Flix-Gandesa y el del mismo río Ebro. La combinación de túmulos planos y campos de urnas presente en Sebes, y ya constatada en Santa Madrona (Belarte y Noguera 2007), permite descartar la antigua división geográfica entre campos de urnas en la costa y túmulos en el interior. Como se ha venido repitiendo en los últimos años, cada vez se documentan más casos donde coexisten distintos tipos de tumbas incluso en una misma necrópolis (López Cachero 2008: 147).

El estudio de las formas de enterramiento muestra que las necrópolis de la Ribera d'Ebre se sitúan en una zona de intenso contacto entre dos tradiciones funerarias: la del Segre-Cinca y la de la Terra Alta y el Bajo Aragón. A nivel local, cada comunidad presenta ciertas peculiaridades propias, dentro de una cierta homogeneidad en las prácticas de enterramiento. Así, la necrópolis de Santa Madrona contiene túmulos cuadrangulares o cistas en el interior de los túmulos planos circulares, mientras que en Sebes solo hay túmulos de este último tipo y urnas aisladas. En cambio, nunca se han documentado los túmulos elevados y de grandes dimensiones característicos de las necrópolis del Bajo Aragón-Terra Alta (Rafel 2003).

Además de las estructuras de enterramiento, en Sebes se documentan construcciones anexas que interpretamos como posibles cenotafios. Se conocen también en las necrópolis coetáneas de Coll del Moro (Rafel 1989: 71), Castellets de Me- 
quinenza II (Royo 1994-1996: 100), Roques de Sant Formatge (Colet et al. 2005a: 155) y Santa Madrona (Belarte y Noguera 2007: 71).

Las dimensiones de los túmulos, entre $1,10 \mathrm{y}$ $1,70 \mathrm{~m}$, de las estructuras de enterramiento documentadas en Sebes se asemejan a las de otras necrópolis de Cataluña meridional y occidental, como Vall de la Clamor (Colet et al. 2005b), Roques de Sant Formatge (Colet et al. 2005a), Coll del Moro (Rafel y Hernández 1992: 38) o Llardecans (Maya 1982: 122-123), entre 1 y 2,2 $\mathrm{m}$ de diámetro. En cambio son muy inferiores a los túmulos de cista excéntrica característicos del Bajo Aragón, con un diámetro medio entre 3 y 5 m (Rafel 2003: 72). El predominio de túmulos planos sin cista con anillos concéntricos de Sebes acerca sus estructuras funerarias a los modelos del tipo Segre-Cinca (López Cachero 2008: 157), caracterizados por túmulos planos con enlosados interiores poco elevados (López Cachero 2008: 147). Ello podría responder a un origen en esta última zona (Ruiz Zapatero 1985: 375-377), aunque por otra parte los túmulos neolíticos de la zona de Mequinenza (Royo 1984) insinúan una evolución a partir de prototipos locales, hasta el momento desconocidos en el entorno de la necrópolis de Sebes.

En resumen, los trabajos realizados hasta el momento en la necrópolis de incineración de Sebes sugieren que cubría unos $200 \mathrm{~m}^{2}$. Tipos diversos de estructuras se agrupan espacialmente en dos áreas, siempre con estructuras tumulares predominantes. Los enterramientos (en túmulo o en urna) alternan con estructuras vacías y urnas con elementos de ajuar pero sin restos óseos. La coexistencia de distintos tipos de estructuras y las agrupaciones espaciales de tumbas aparecen en otras necrópolis coetáneas de la zona, aunque la distribución de los enterramientos en Sebes presenta algunas particularidades. La duración de la necrópolis, según los materiales cerámicos y metálicos, se sitúa entre el siglo VII y la primera mitad del VI a.C. Ello confirmaría su contemporaneidad con el hábitat del Hierro I identificado en el cerro contiguo. Esa datación no coincide, en cambio, con las fechaciones de C14, que sugieren la perduración del cementerio en época ibérica. Ello puede ser debido a los problemas inherentes al método para este periodo, pero también puede indicar la reutilización de algunas tumbas. El estudio antropológico revela que las sepulturas contenían un solo individuo, salvo tres enterramientos dobles, dos de los cuales pueden ser reutilizaciones.

Las investigaciones del equipo en las necrópolis de Santa Madrona y Sebes contribuyen a llenar el vacío que hasta hace pocos años presentaba el área de la Ribera d'Ebre en el panorama del mundo funerario del Hierro I. El análisis de ambas necrópolis muestra que, tanto desde el punto de vista tipológico como ritual, se relacionan con el área cultural del Segre-Cinca.

\section{AGRADECIMIENTOS}

El desarrollo de este proyecto ha sido posible gracias al soporte del Ayuntamiento de Flix, de la asociación La Cana, la Agència de Gestió d'Ajuts Universitaris i de Recerca (AGAUR) (proyectos 2005ACOM 00037, 2007ACOM00033 y 2009ACOM00005) y el Departamento de Cultura de la Generalitat de Catalunya (convocatorias para intervenciones arqueológicas programadas entre el 2006 y el 2012).

El estudio de una muestra de materiales metálicos de Sebes se han realizado en el marco del proyecto coordinado "El factor minero en el desarrollo histórico de Cataluña meridional: de la Prehistoria a época medieval" (HAR201021105-C02-00). Agradecemos a Núria Rafel y a Ignacio Montero, investigadores responsables, respectivamente, de los subproyectos "Procesos sociales, tecnológicos y económicos en la explotación de recursos minerales del Priorat (Cataluña): una visión diacrónica" (HAR2010-21105-C02-01) y "Relación entre materias primas locales y producción metalúrgica: Cataluña meridional como modelo de contraste" (HAR2010-21105-C02-02), el acceso a la información sobre los resultados así como los análisis mencionados.

\section{BIBLIOGRAFÍA}

Agustí, B.; Codina, D.; Dehesa, R.; Llinàs, J.; Merino, J.; Montalbán, C. y Vargas, A. 2004: "Excavacions arqueològiques a Vilanera (1’Escala Alt Empordà). Tribuna d'Arqueologia 2000-2001: 99-114.

Agustí, B. 2008: "Estudi antropològic de les incineracions". En R. Graells: La necròpolis protohistòrica de Milmanda (Vimbodí, Conca de Barberà, Tarra-

Trab. Prehist., 70, N. ${ }^{\circ}$ 2, julio-diciembre 2013, pp. 295-314, ISSN: 0082-5638

doi: $10.3989 /$ tp.2013.12114 
gona). Un exemple del món funerari català durant el trànsit entre els segles VII $i$ VI aC. Hic et Nunc 5 , Institut Català d'Arqueologia Clàssica. Tarragona: 131-134.

Barrachina, A.; Vizcaíno, D.; Viciach, A.; Pérez, R.; Agustí, B.; Arquer, N.; Sanchís, A.; Hernández, F. J. y Tormo, C. 2010: "La necrópolis tumular de Sant Joaquim de la Menarella de Forcall, comarca dels Ports (Castellón)". En F. Burillo (ed.): Ritos y mitos: VI Simposio sobre Celtiberos (Daroca 2008): 341- 350. Zaragoza.

Belarte, M. C. y Noguera, J. 2007: La necròpolis protohistòrica de Santa Madrona (Riba-roja d'Ebre, Ribera d'Ebre). Hic et Nunc 2, Institut Català d'Arqueologia Clàssica. Tarragona.

Belarte, M. C. y Noguera, J. 2008: "El jaciments protohistòrics de Santa Madrona (Riba-roja) i Sebes (Flix), Ribera d'Ebre'. Tribuna d'Arqueologia 2007: 127-147.

Belarte, M. C.; Noguera, J. y Olmos, P. 2012a: “Aportaciones al proceso de iberización en el curso inferior del Ebro: el ejemplo de Sebes (Flix, Ribera d'Ebre)". Iberos del Ebro, II Congreso Internacional (Alcañiz-Tivissa 2011). Serie Documenta 25, Institut Català d'Arqueologia Clàssica: 95-102.

Belarte, M. C.; Noguera, J.; Olmos, P. y Cervelló, F. 2012b: "La necròpolis protohistòrica de Sebes (Flix, Ribera d'Ebre)". En M. C. Rovira Hortalà, F. J. López Cachero y F. Mazière (eds.): Les Necròpolis d'incineració entre l'Ebre $i$ el Tíber (segles IX-VI $a C)$ : metodologia, pràctiques funeràries $i$ societat. Monografies Museu d'Arqueologia de CatalunyaBarcelona 14. Barcelona: 95-101.

Bronk Ramsey, C. 2001: "Development of the radiocarbon calibration program OxCal". Radiocarbon 43 (2A): 355-363.

Bronk Ramsey, C. 2009: "Bayesian analysis of radiocarbon dates". Radiocarbon 51 (1): 337-360.

Carlús, X.; López Cachero, F. J.; Oliva, M.; Palomo, A.; Rodríguez, A.; Terrats A.; Lara, C. y Villena, N. 2007: Cabanes, sitges $i$ tombes. El paratge de Can Roqueta (Sabadell, Vallès Occidental) del 1300 al 500 ANE. Quaderns d'Arqueologia 4, Museu d'Història de Sabadell.

Castro Martínez, P. V. 1994: La sociedad de los Campos de Urnas en el nordeste de la Península Ibérica. La necrópolis de El Calvari (El Molar, Priorat, Tarragona). British Archaeological Reports, International Series 592, Archaeopress. Oxford.

Colet, A.; Gené, M. y GIP 2005a: "El món funerari durant el Grup del Segre-Cinca III (950-750 cal a.n.e.): la necròpolis de Roques de Sant Formatge (Seròs, el Segrià)". Revista d'Arqueologia de Ponent 15: 151-165.

Colet, A.; Lafuente, A. y GIP 2005b: “Avenç sobre una nova necròpolis tumular d'incineració del Grup del Segre-Cinca: la Vall de la Clamor (Soses, el Segrià)". Revista d'Arqueologia de Ponent 15: 165-177.
Fadrique, T. y Malgosa, A. 2007: "Estudi antropològic de les unitats funeràries procedents de la necrópolis de cremació de Santa Madrona”. En M. C. Belarte y J. Noguera: La necròpolis protohistòrica de Santa Madrona (Riba-roja d'Ebre, Ribera d'Ebre). Hic et Nunc 2, Institut Català d'Arqueologia Clàssica. Tarragona: 93-106.

Garcia i Rubert, D. y Moreno, I. 2008: "Marcadors socials durant el primer ferro a Catalunya i al País Valencià. Apunts en relació a l'assentament de Sant Jaume (Alcanar, Montsià). En M. Miñarro y S. Valenzuela (eds.): Actes del I Congrés de Joves Investigadors en Arqueologia dels Països Catalans: la protohistòria als Països Catalans (Vilanova del Camí, 18 i 19 de novembre de 2005). Arqueo Mediterrània 10, Universitat de Barcelona: 215-225.

Genera, M. 1982: "Inventari arqueològic de la Ribera d'Ebre". Fonaments 3, 47-134.

López Cachero, J. 2007: "Sociedad y economía durante el Bronce Final y la Primera Edad del Hierro en el noreste peninsular: una aproximación a partir de las evidencias arqueológicas". Trabajos de Prehistoria 64 (1): 99-120.

López Cachero, J. 2008: "Necrópolis de incineración y arquitectura funeraria en el noreste de la Península Ibérica durante el Bronce Final y la Primera Edad del Hierro". Complutum 19: 139-171.

Mascort, M. T.; Sanmartí, J. y Santacana, J. 1991: El Jaciment protohistòric d'Aldovesta, Benifallet, i el comerç fenici arcaic a la Catalunya meridional, $\mathrm{Pu}-$ blicacions de la Diputació de Tarragona. Tarragona.

Maya, J. L. 1982: "Dos necrópolis de incineración en el Bajo Segre: Llardecans y La Femosa", Ilerda 43: 119-151.

Montero-Ruiz, I.; Rafel, R.; Rovira, M. C.; Armada, X. L.; Graells, R.; Hunt, M.; Murillo-Barroso, M.; Renzi, M. y Santos, M. 2012: "El cobre de Linares (Jaén) como elemento vinculado al comercio fenicio en El Calvari de El Molar (Tarragona)". Menga 3: 167-185.

Navarro, R. 1970: Las fibulas en Catalunya. Publicaciones Eventuales 16, Barcelona.

Parker Pearson, M. 1999: The Archaeology of Death and Burial. Texas A\&M University Press. Texas.

Piga, G; Thompson, T. J. U; Malgosa, A; Enzo, S. 2009: "The Potential of X-Ray Diffraction in the Analysis of Burned Remains from Forensic Contexts". Journal of Forensics Sciences (3): 534-539.

Pita, R. 1950: "Sobre la localización de Octogesa en Riba-roja". Butlletí Arqueològic de Tarragona 50, època IV: 3-9.

Pita, R. y Díez-Coronel, L. 1968: La necrópolis de 'Roques de Sant Formatge', en Serós (Lérida) Excavaciones Arqueológicas en España 59, Ministerio de Educación y Ciencia. Madrid.

Pons, E. y Solés, E. 2008: La necròpolis d'incineració del Pi de la Lliura (Vidreres) ara fa 3.000 anys. Ajuntament de Vidreres. Girona. 
Rafel, N. 1989: La necròpolis del Coll del Moro de Gandesa. Les estructures funeràries. Col·lecció Monografies 1, Ajuntament de Tarragona. Tarragona.

Rafel, N. 1991: La necròpolis del Coll del Moro de Gandesa. Els materials. Publicacions de la Diputació de Tarragona. Tarragona.

Rafel, N. 2003: Les necròpolis tumulàries de tipus baixaragonès: les campanyes de l'Institut d'Estudis Catalans al Matarranya. Monografies 4, Museu d'Arqueologia de Catalunya- Barcelona. Barcelona.

Rafel, N. y Armada, X. L. 2008: "Sobre la cronologia de la necròpolis del Calvari del Molar i l'horitzó funerari del bronze final - primera edat del ferro a l'Ebre. Noves datacions absolutes". Cypsela 17: 149-159.

Rafel, N. y Hernàndez, G. 1992: "Pràctiques funeràries a la necròpolis del Coll del Moro (Gandesa, la Terra Alta)". Revista d'Arqueologia de Ponent 2: 37-55.

Rafel, N.; Vives-Ferrándiz, J.; Armada, X. L. y Graells, R. 2008: "Las comunidades de la Edad del Bronce entre el Empordà y el Segura: espacio y tiempo de los intercambios". En S. Celestino, N. Rafel y X. L. Armada (eds.): Contacto cultural entre el Mediterráneo y el Atlántico (siglos XII-VII ane): la precolonización a debate. CSIC, Escuela Española de Historia y Arqueología en Roma. Madrid: 239-271.

Rovira Hortalà, M. C.; López Cachero, J. y Mazière, F. 2012: Les Necròpolis d'incineració entre l'Ebre $i$ el Tíber (segles IX-VI a. C.): metodologia, pràctiques funeràries i societat. Monografies Museu d'Arqueologia de Catalunya-Barcelona 14, Barcelona.

Royo, J. I. 1984. "Excavaciones del Museo de Zaragoza en la necrópolis prehistórica del Barranco de la Mina Vallfera, Mequinenza, Zaragoza". Boletín del Museo de Zaragoza 3: 5-22.

Royo, J. I. 1994-1996: "Ritual funerario y cultura material en las necrópolis tumulares de los Castellets de Mequinenza (Zaragoza): una aportación al estudio del Bronce final/Hierro en el N.E. peninsular". Gala 3-5, 93-108.

Ruiz Zapatero, G. 1985: Los Campos de Urnas del N.E. de la Península Ibérica. Tesis doctoral 83/85, Universidad Complutense de Madrid. Madrid.

Ruiz Zapatero, G. 2001: "Las comunidades del Bronce Final: enterramientos y sociedad en los campos de urnas". En M. Ruiz-Gálvez (coord.): La Edad del
Bronce, ¿Primera Edad de Oro en España? Crítica Arqueología. Barcelona: 257-288.

Ruiz Zapatero, G. 2004: “Casas y tumbas. Explorando la desigualdad social en el Bronce Final y la Primera Edad del Hierro del NE de la Península Ibérica”. Mainake XXVI: 293-330.

Sanmartí, J. 2005: "La conformación del mundo ibérico septentrional". Acta Palaeohispanica IX. Palaeohispanica 5: 333-358.

Sanmartí, J.; Asensio, D.; Belarte, M. C.; Martín, A.; Santacana, J. 2006: "La iberització a la Catalunya costanera i central". En M. C. Belarte y J. Sanmartí (eds.): De les comunitats locals als estats arcaics: la formació de les societats complexes a la costa del Mediterrani occidental. Homenatge a Miquel Cura. Actes de la III Reunió Internacional d'Arqueologia de Calafell (Calafell 2004). Arqueo Mediterrània 9, Universitat de Barcelona. Barcelona: 145-163.

Sanz, M. 1973-74: "Población ibérica del valle del Ebro". Butlletí Arqueològic de Tarragona, època IV: $11-22$.

Subirà, E. y Ruíz, J. 2008: "Les restes antropològiques”. En E. Pons y A. Solés (dirs.): La necròpolis d'incineració del Pi de la Lliura-Vidreres. Ajuntament de Vidreres y Museu d'Arqueologia de Catalunya-Girona. Girona: 111-121.

Toledo, A. y Palol, P. 2006: La necròpolis d'incineració del bronze final transició a l'edat del ferro de Can Bech de Baix, Agullana (Alt Empordà, Girona). Els resultats de la campanya d'excavació de 1974. Sèrie Monogràfica 24, Museu d'Arqueologia de Catalunya-Girona. Girona.

Vázquez, M. P.; Medina, J. y González, J. R. 2012: "La Pedrera (Vallfogona de Balaguer-Térmens). Cinquanta anys després". En M. C. Rovira Hortalà, J. López Cachero y F. Mazière (eds.): Les Necròpolis d'incineració entre l'Ebre i el Tíber (segles IX-VI $a C)$ : metodologia, pràctiques funeràries $i$ societat. Monografies Museu d'Arqueologia de CatalunyaBarcelona 14, Barcelona: 103-110.

Vilaseca, S. 1943: El poblado y necrópolis prehistórica de Molà (Tarragona). Acta Arqueológica Hispánica I. Madrid.

Vilaseca, S. 1956: "El campo de urnas de la Tosseta (Guiamets)". IV Congreso Internacional de Ciencias Prehistóricas y Protohistóricas (Madrid 1954): 841-856. Madrid. 